\title{
Inscribir el declive en el tiempo. Detroit: Auge y crisis de la Ciudad Industrial ${ }^{1}$
}

\author{
Beatriz FERNÁNDEZ ÁGUEDA \\ Escuela Técnica Superior de Arquitectura \\ Universidad Politécnica de Madrid \\ b.fagueda@upm.es
}

Recibido: 5 de junio del 2015

Enviado a evaluar: 22 de junio del 2015

Aceptado: 14 de septiembre del 2015

\section{RESUMEN}

A comienzos del siglo XX, Detroit era una ciudad dinámica en pleno desarrollo. Pronto se convirtió en la cuarta ciudad de Estados Unidos, la capital de la naciente industria automovilística. El crecimiento se prolongó hasta finales de los años 50, cuando, a pesar del auge económico de Estados Unidos y de su área metropolitana, Detroit comenzó a mostrar los primeros signos de estancamiento. La crisis se ha prolongado hasta hoy, cuando Detroit constituye el paradigma de la ciudad industrial en declive. Estas dos imágenes contrapuestas, el auge y la crisis, no parecen explicar por sí mismas las causas de la intensidad y persistencia del declive de Detroit. Analizar las interacciones entre crecimiento económico, políticas públicas locales y desarrollo urbano a lo largo del tiempo permitirá subrayar las continuidades y comprender en qué medida el declive de Detroit ancla sus raíces en el modelo planteado durante la etapa de auge.

Palabras clave: Declive, urbanismo, ciudad industrial, historia urbana.

\section{Register the decline in time. Detroit: The rise and crisis of Industrial City}

\begin{abstract}
At the beginning of the 20th century, Detroit was a dynamic rising city. It was the fourth largest city in the United States, the capital of the automobile industry. City's growth lasted till the 1950s, when the first signs of stagnation appeared despite the economic boom of the country and its metropolitan area. This crisis persists until today, when Detroit has become the symbol of industrial cities in decay. These
\end{abstract}

${ }^{1}$ Este artículo sintetiza los resultados de uno de los casos de estudio de la tesis doctoral "Futuros urbanos: la reversibilidad del proceso de deterioro", realizada en la Escuela Técnica Superior de Arquitectura de la Universidad Politécnica de Madrid bajo la dirección del profesor Javier Ruiz Sánchez y presentada en marzo de 2013. La investigación se realizó gracias a una estancia como Visiting Scholar en Columbia University en 2011. 
two divergent images (boom and crisis) seem unable to explain by themselves the intensity and persistence of Detroit's decline. Cross-analysis of the interactions between economic growth, public policies and urban transformations on the long term will emphasize the continuities in urban development. It will also allow comprehending the effects of growth process on subsequent decline.

Key words: Decline, urban planning, industrial city, urban history.

Inscrivez déclin du temps.

Detroit : La montée el la crisis des Industriels Ville

\section{RÉSUMÉ}

Dans le début du XXe siècle, Detroit était une ville animée en plein essor. Bientôt, il est devenu la quatrième ville des États-Unis, la capitale de l'industrie automobile naissante. La croissance a continué jusqu'à la fin des années 50, lorsque, malgré le boom économique aux États-Unis et sa région métropolitaine, Detroit a commencé à montrer les premiers signes de stagnation. La crise a duré jusqu'à aujourd'hui, où Detroit est le paradigme de la ville industrielle en déclin. Ces deux images contrastées, le boom et la crise ne semblent pas eux-mêmes expliquer les causes de l'intensité et la persistance de la baisse de Detroit. Analyser les interactions entre la croissance économique, les politiques publiques locales et le développement urbain dans le temps permettent de souligner les continuités et de comprendre dans quelle mesure la baisse de Detroit ancre ses racines dans le modèle proposé au cours de la phase d'expansion.

Mots clés: Déclin, urbanisme, ville industrielle, l'histoire urbaine.

\section{INTRODUCCIÓN}

A comienzos del siglo XX, Detroit era una ciudad dinámica en pleno desarrollo. En las dos primeras décadas del siglo, pasó de ser una capital regional de menos de 300.000 habitantes a convertirse en la cuarta ciudad de Estados Unidos con casi un millón. A pesar de que en 1920 ya era conocida como The Motor City, la capital de la naciente industria automovilística, su base productiva estaba constituida por una multiplicidad de sectores industriales (de la industria alimentaria, farmacéutica o textil a la mecánica y la maquinaria) y empresas (del pequeño taller familiar a las nuevas grandes fábricas de Ford) que conformaban una estructura económica resistente y compleja. El auge de la industria atrajo durante décadas un flujo continuo de inmigrantes y el crecimiento económico, demográfico y urbano se prolongó hasta después de la Segunda Guerra Mundial.

En 2013, esta misma ciudad fue la primera gran metrópolis en la historia de Estados Unidos en declararse en quiebra. Los resultados del censo 2010 habían alertado meses antes a la opinión pública. La tasa de pobreza se elevaba al 38.1\%, seis puntos por encima que en 2006, y la ciudad había perdido más de doscientos mil habitantes en una década, aproximadamente un tercio de su población.

Estas dos imágenes, la del auge y la de la crisis, son las que han caracterizado el estudio de Detroit que ha tendido a vincular exclusivamente el declive de la ciudad con el ocaso de la industria automovilística americana. Estos dos momentos 
singulares han sido examinados en numerosas ocasiones (Darden et Al, 1987; Hill, 1996; Thomas, 1988; Thomas, 1990; Zunz, 1982), pero son muchos menos los análisis que hayan tratado de buscar las articulaciones entre ellos. No obstante, la ciudad en auge y la ciudad en declive no constituyen dos hechos urbanos diferentes, sino que, como Marcel Poëte señalaba para París, "se trata de un solo ser en constante evolución” (Poëte: 1927-1931, vol. I: I). Examinar el declive como un proceso aislado en el tiempo y en el espacio permite desvincularlo de la continuidad de las dinámicas territoriales y asociar la crisis exclusivamente a dinámicas externas y globalizadoras.

El objetivo de este artículo es, precisamente, subrayar las continuidades que permitan comprender el declive como una etapa de la evolución urbana de Detroit e inscribirlo en el proceso más amplio de desarrollo regional. Si bien es imposible negar la influencia de las dinámicas macroeconómicas y las tendencias globales, analizar las interacciones entre crecimiento económico, políticas públicas y desarrollo urbano mostrará en qué medida el declive de Detroit ancla sus raíces en el modelo local desarrollado en la etapa de auge.

\section{LA CONSTRUCCIÓN DE LA CIUDAD INDUSTRIAL}

Situada en una región rica en materias primas y en una posición estratégica, el desarrollo de Detroit en el siglo XIX se vinculó al auge de la industria. El "sistema industrial de escala regional” (Meyer, 2001: 146) previo a la Guerra de Secesión, diversificado y vinculado a la transformación de productos de la región y al consumo local, se transformó progresivamente gracias a los avances tecnológicos, a la mejora de los medios de transporte y a la aparición de los mercados interregionales. Esta evolución, similar a la de otras muchas ciudades del cinturón manufacturero de Estados Unidos, estuvo ligada a la construcción progresiva de unos nuevos sistemas urbanos que se especializaron en sectores industriales en auge y atendieron al mercado nacional incrementando la producción. Sin embargo, la especialización de Detroit en la industria automovilística fue relativamente tardía ya que cuando ésta inició su expansión a principios del siglo XX, Detroit era ya un importante centro de producción (Leonard, 1887: 24).

Reconstruir este paisaje industrial en toda su complejidad y contextualizar la llegada del sector del automóvil parece importante en esta primera parte de la investigación, para comprender en qué medida la especialización en la producción automovilística y en la producción en masa, transformaron en profundidad su estructura urbana y su espacio social.

\subsection{EL NACIMIENTO DE THE MOTOR CITY}

En el cambio de siglo, antes de la irrupción del sector automovilístico, Detroit era ya una importante ciudad industrial. La accesibilidad a las materias primas, la disponibilidad de terrenos a lo largo de la ribera del río, los bajos impuestos y la presencia de capital local habían favorecido el desarrollo industrial desde finales del 
siglo XIX (Farmer, 1884; Leonard, 1887). En 1900, algunos sectores tradicionales (textil, alimentaria, tabaco, madera) habían comenzado a decaer, pero otras industrias emergentes (farmacéutica, química o las imprentas), compensaron su estancamiento y la ciudad continuó creciendo (U.S Bureau of the Census, 1900). El desarrollo más significativo fue, no obstante, el de la industria del transporte. A principios de siglo existía en Detroit una red productiva compleja de fabricación de vehículos de ferrocarril (de la transformación de las materias primas de la región a la fabricación de componentes y el montaje de los vagones). Este tejido productivo configuró, a lo largo del tiempo, una cultura obrera específica, unos modos de producir y de organizar el trabajo que quedaron espacializados en el territorio de Detroit (Zunz, 1982).

Figura 1. Detroit en 1914. Ribera del río ocupada por la industria.

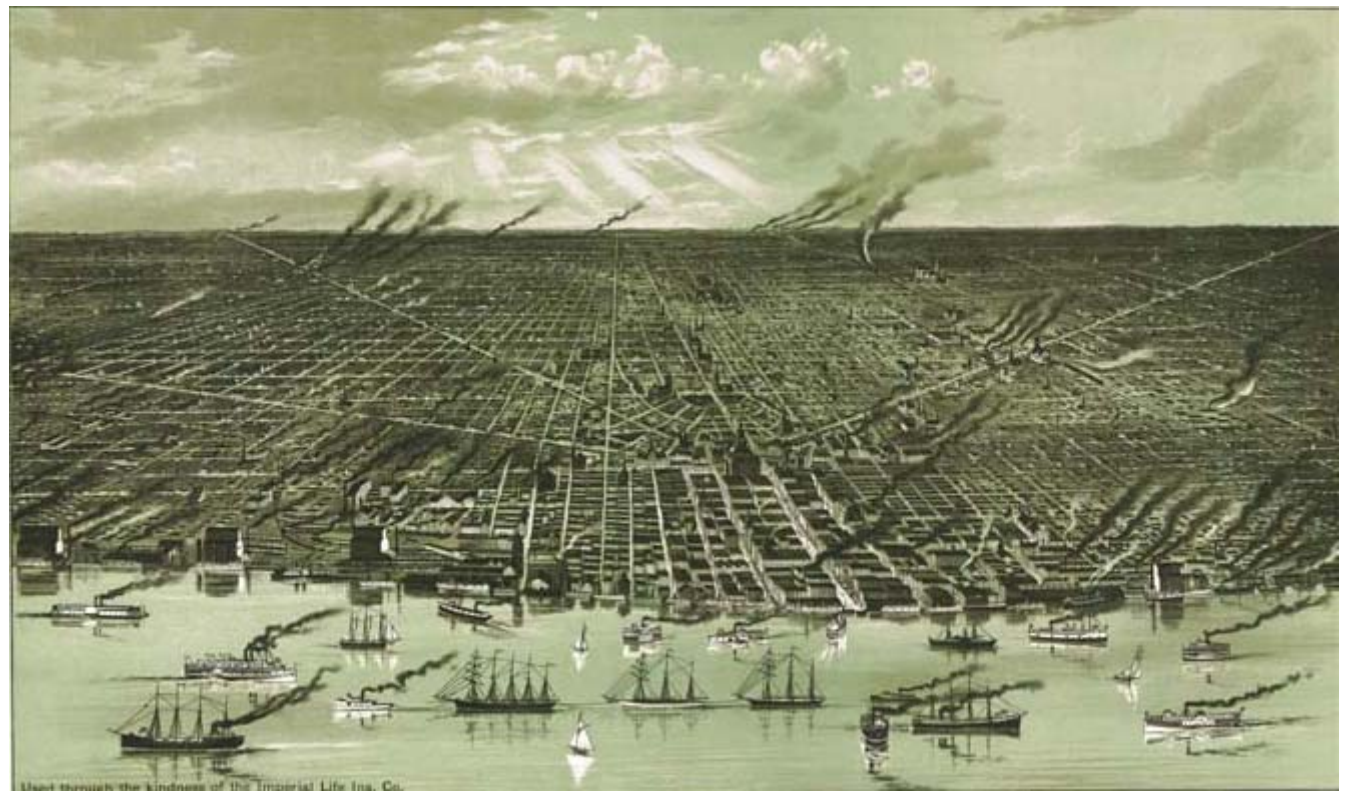

Fuente: Detroit City Plan and Improvement Commission (1914), plate 1.

La variedad de sectores, productos, empresas, procedencias y formas de trabajo configuraron una base productiva de excepcional complejidad y muy resistente a las crisis sectoriales, que sufrió una progresiva especialización durante el siglo XX. Nuestra hipótesis, alineada con las conclusiones del estudio de Friedrichs (Friedrichs, 1993), es que la simplificación progresiva de este tejido complejo, hizo progresivamente más vulnerable a Detroit a las fluctuaciones y crisis de la industria dominante y condujo, a largo plazo, a un proceso declive especialmente persistente y grave. 
Las formas urbanas adoptadas por esta compleja estructura industrial fueron múltiples, pero es posible diferenciar, ya desde finales del siglo XIX, dos patrones básicos de localización industrial en función del tipo de empresa y de los modos de producción. La pequeña industria (producción de bienes de consumo, pequeñas empresas tradicionales y nuevos sectores innovadores de pequeña dimensión empresarial como la fabricación de maquinaria eléctrica o la impresión y la publicación) necesitaba de la actividad y proximidad del centro urbano para establecer relaciones de cooperación y fijar a la mano de obra cualificada.

Por el contrario, el principal requerimiento de las nuevas grandes manufacturas era una localización idónea respecto a las redes de transporte que les permitieran conectar con sus economías de escala. Ya desde finales del siglo XIX, las fábricas de mayores dimensiones, las empresas que necesitaban del agua en sus procesos productivos y la industria habían ocupado la ribera del río. A medida que se desarrolló la red de ferrocarril y los costes del transporte ferroviario se redujeron, ésta se convirtió en el espacio privilegiado de la industria. Las nuevas grandes empresas del transporte, la mecánica, la metalurgia o la química se ubicaron de forma dispersa a los lados de las líneas de ferrocarril ya en el cambio de siglo, pero fue sobre todo el sector automovilístico el que inició una clara tendencia a la descentralización a partir de 1910.

El trazado del nuevo ferrocarril de cintura, muy alejado de la zona urbanizada, impulsó este patrón disperso, vinculado exclusivamente a las condiciones de accesibilidad y a la oportunidad de adquirir terrenos a bajo coste. Las nuevas fábricas automovilísticas (sobre todo las de las empresas que ya comenzaban a liderar el sector, Ford y Chrysler) constituyeron nuevas centralidades en la periferia que atrajeron a empresas proveedoras y obreros.

La descentralización de la industria y la construcción de la línea de cintura introdujeron un problema para el Ayuntamiento de Detroit, que vio cómo las áreas de crecimiento probable de la actividad productiva se situaban fuera de su término municipal. Las políticas de anexión de terrenos colindantes que el Ayuntamiento había llevado a cabo desde las últimas décadas del siglo XIX se intensificaron en estos años ${ }^{2}$, pero el objetivo de las operaciones había cambiado. Si anteriormente la anexión se había vinculado a las necesidades de extensión de un término municipal en pleno crecimiento, a partir de entonces, el objetivo fue captar el crecimiento económico y asegurar que éste revirtiera en el municipio. Las continuas anexiones llevadas a cabo durante las primeras décadas del siglo XX consumieron gran parte de los presupuestos del municipio.

${ }^{2}$ Detroit duplicó su superficie entre 1865 y 1900, alcanzando casi las $6.000 \mathrm{Ha}$ 
Figura 2. Localización de la industria de Detroit por sectores (1920).

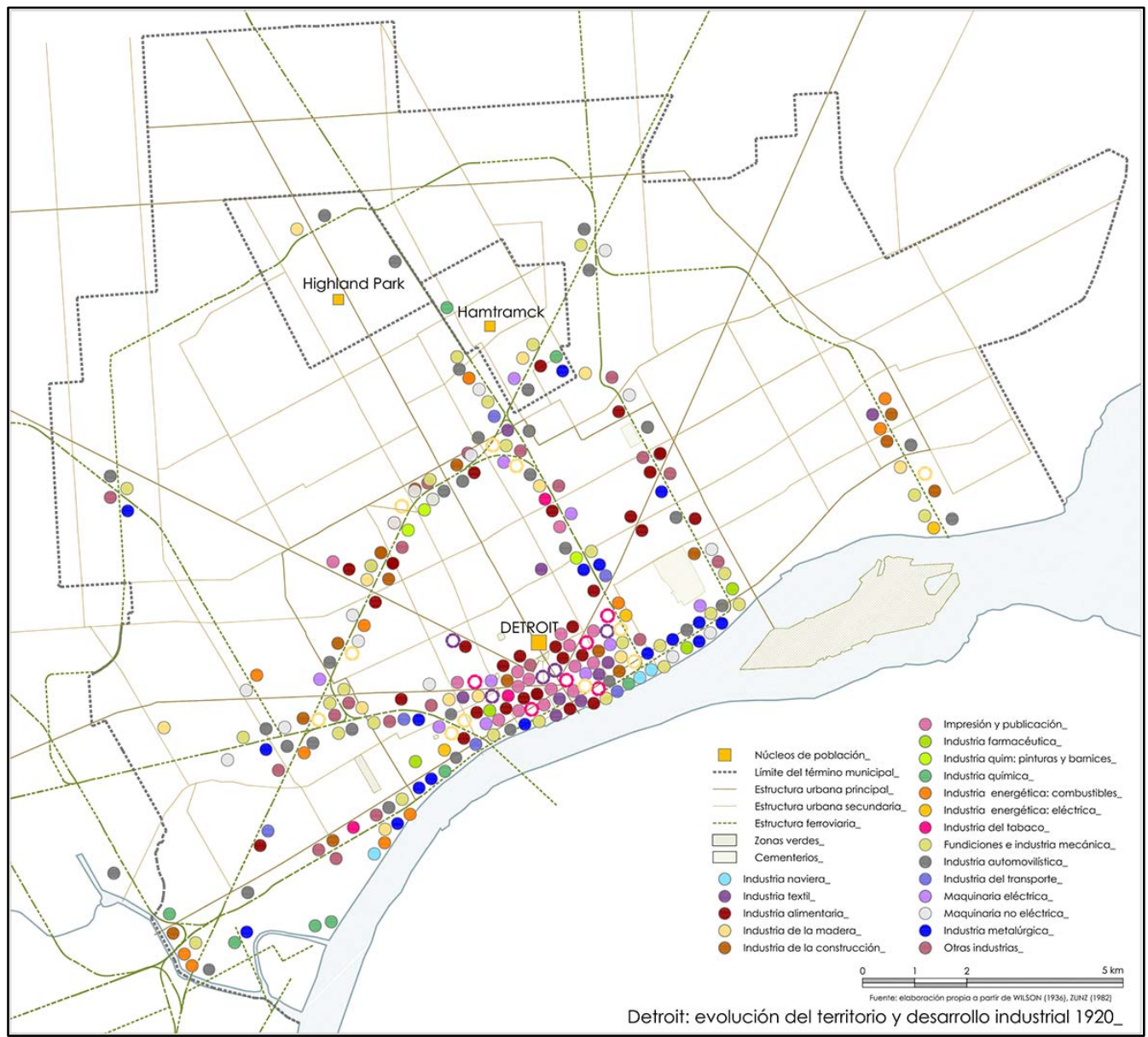

Fuente: Elaboración propia.

\subsection{TRANSFORMACIONES PRODUCTIVAS Y ESPACIO SOCIAL: PRIMERAS TENTATIVAS DE INTERVENCIÓN}

El auge económico y la necesidad de mano de obra de la industria provocaron una continua afluencia de población inmigrante. Entre 1860 y 1910, Detroit multiplicó su población por diez, pasando de ser una pequeña capital de provincias a la novena ciudad de Estados Unidos con casi quinientos mil habitantes. 
Cuadro 1. Evolución de la población de Detroit (1860 - 1910).

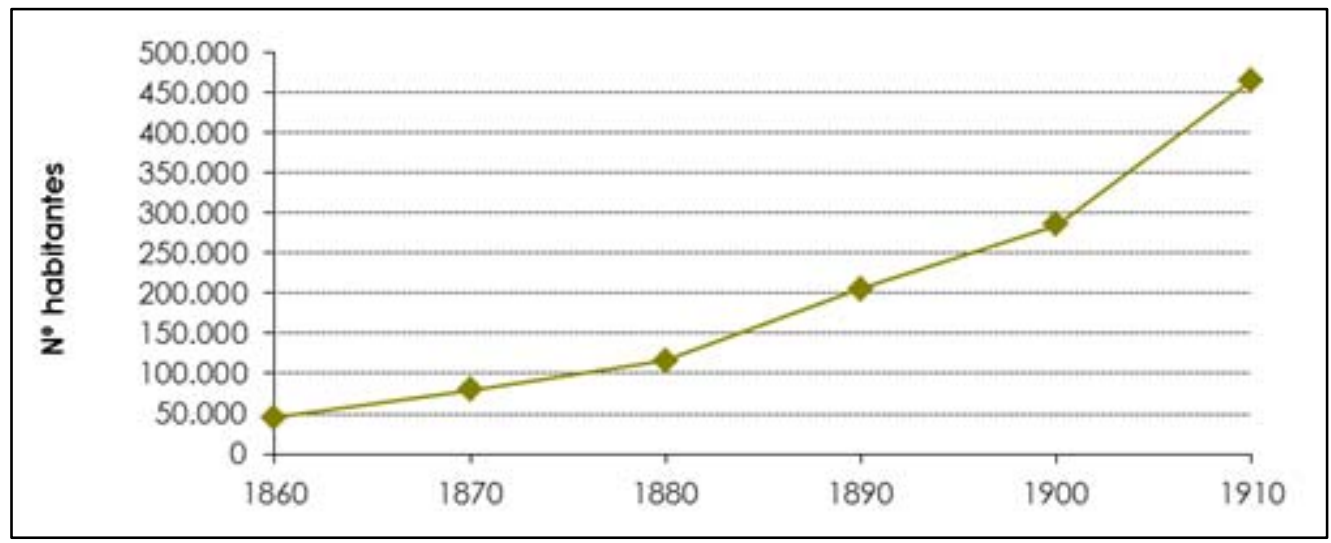

Fuente: Elaboración propia.

Sin embargo, las transformaciones socioespaciales impulsadas por la industrialización no estuvieron únicamente vinculadas al crecimiento demográfico y al consecuente desarrollo de la ciudad, sino principalmente a una progresiva diferenciación del espacio urbano por clase. Hasta comienzos de siglo se había producido una concentración por comunidades de origen. El barrio alemán, el barrio polaco o el barrio irlandés funcionaban como microcosmos dentro de la ciudad, con cierto nivel de independencia y control del espacio; a los lazos afectivos se sumaban los vínculos económicos y de propiedad. Las distintas comunidades étnicas dominaban ciertas profesiones y establecían mecanismos informales de asistencia y cooperación entre sus miembros, desarrollando estructuras de reproducción social que permitían a los trabajadores adaptarse a las nuevas condiciones de producción (Zunz, 1982: 171).

No obstante, el modelo de la producción en masa y la gran empresa industrial impuso una homogeneización de la población obrera, que ya no se distinguió por sus cualificaciones. Progresivamente, los vínculos de clase y categoría profesional comenzaron a prevalecer sobre los lazos de origen, transformando profundamente el espacio social de Detroit. En 1920, las comunidades étnicas se habían disuelto y la localización de los distintos grupos sociales en la ciudad estaba determinaba, en gran medida, por el mercado inmobiliario y la ubicación respecto a las fábricas. Progresivamente se impuso una diferenciación del espacio por clase y tan sólo la comunidad negra permaneció concentrada, debido a la segregación racial, en la zona más pobre y deteriorada de la ciudad. Detroit pasó así, en pocos años, de ser una ciudad dividida en barrios étnicos complejos a adoptar un modelo especializado funcionalmente y segregado socialmente, idóneo para los requerimientos de empleo de la nueva industria (Zunz, 1982). 
El crecimiento residencial se produjo principalmente en extensión de vivienda unifamiliar y en continuidad con la trama consolidada. El incremento de población también dio lugar a una densificación del centro pero, frente a la colmatación característica de otras ciudades industriales ${ }^{3}$, en Detroit el problema más grave no fue el incremento de densidad, sino la falta de regulación de la localización industrial. A medida que las nuevas fábricas se diseminaban por la ciudad y la población continuaba creciendo, las élites urbanas comenzaron a trasladarse a enclaves de la periferia norte y noreste alejados de la industria. Las clases medias de trabajadores no manuales se situaron en las afueras de Detroit, en nuevos barrios de vivienda unifamiliar, mientras que el centro concentró a la población obrera inmigrante.

La división del espacio urbano por clase era ya patente a principios del XX. Sin embargo, las desigualdades entre centro y periferia se incrementaron de forma notable en las décadas siguientes. Éstas no sólo se vincularon a la ubicación respecto a la industria o a las diferencias de densidad, sino fundamentalmente en el acceso a los servicios. El gobierno local concentró durante años los recursos en la anexión de territorio y en dotar de equipamientos e infraestructuras a las nuevas zonas residenciales de la periferia destinadas a las clases medias y altas. Por el contrario, los habitantes del centro sufrieron tanto los problemas de tráfico y la incidencia de la actividad industrial como la carencia de servicios, que no se habían ampliado o renovado a pesar de la densificación.

A diferencia de otras ciudades americanas que habían impulsado la construcción de sistemas de parques desde finales del siglo XIX, en Detroit no existieron iniciativas para dotar a la gran ciudad industrial de una red de espacios libres adaptada a las nuevas condiciones de la gran ciudad industrial ${ }^{4}$. Todos los planes y programas de la Detroit City Plan Commission de aquellos años estuvieron destinados a evitar los que se consideraban los dos mayores problemas de la ciudad: el tráfico y la mezcla de usos. Sin embargo, apenas pudieron evitar la dispersión de la industria (Detroit City Plan Commission, 1919)

Los problemas de las clases obreras también se vincularon a la dificultad de acceso a los nuevos espacios de trabajo. Aunque las fábricas que empleaban a un mayor número de trabajadores se alejaron progresivamente del centro y de las zonas residenciales, el municipio no desarrolló una red de transporte público eficaz para lo que ya era una gran metrópolis industrial. Si bien el servicio de tranvías se amplió durante estos años, el gobierno local renunció continuadamente a la construcción de

${ }^{3}$ La densidad media de Manhattan en 1880 era de 37,47 hab/Ha pero algunos barrios superaban los 100 hab/Ha. La densidad máxima de Detroit, en el centro de la ciudad, era de 24,3 hab/Ha. A 2-3 km del centro, la densidad se reducía ya a 5,5 hab/Ha (Zunz, 1982, p.31)

${ }^{4}$ La única actuación relevante en términos de creación de espacios libres fue la transformación en parque de una gran isla situada en el río Detroit, en 1883. El diseño fue encargado a Frederick Law Olmsted. No se plantearon en cambio propuestas de sistemas de parques al modo de los propuestos por el propio Olmsted en Buffalo o en Boston 
una red de metro ${ }^{5}$. Por el contrario, el apoyo al automóvil privado fue muy importante. El Ayuntamiento se apoyó en la financiación estatal del Federal Highway Act de 1921 para construir una red arterial de carreteras que estuvo durante años sobredimensionada y que constituyó el soporte idóneo para el crecimiento suburbano y la descentralización de la industria de los años siguientes ${ }^{6}$.

Figura 3. Plan de carreteras de Detroit.

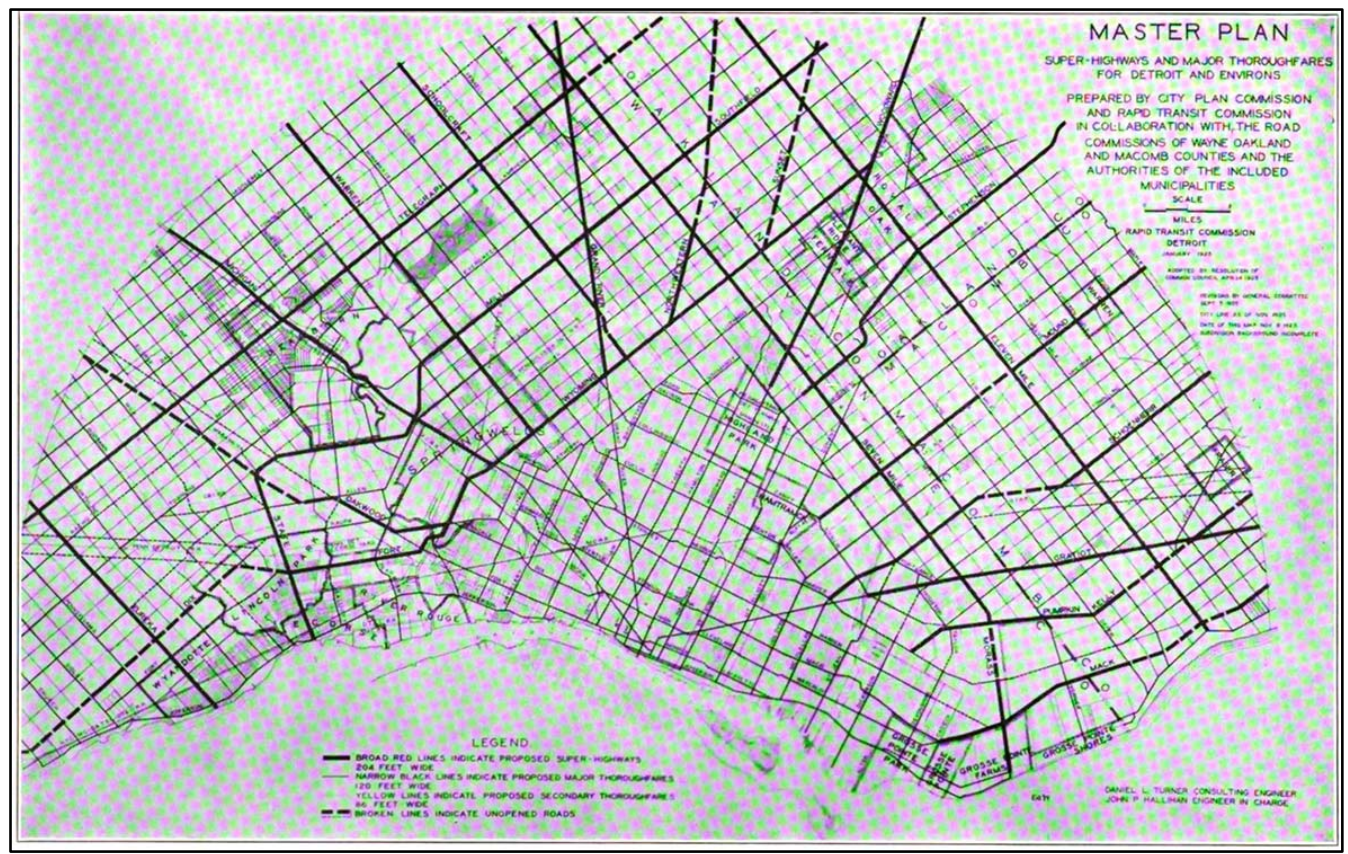

Fuente: Rapid Transit Commission, Proposed Super-Highway Plan for Greater Detroit. April, 1924, p.9.

El proceso de industrialización introdujo en Detroit, al igual que en otras ciudades, un modelo espacial caracterizado por un incremento progresivo de las desigualdades sociales y de las diferencias por etnia y clase. Sin embargo, estos primeros ejemplos de intervenciones públicas sectoriales, o de su llamativa ausencia, como en el caso del

\footnotetext{
${ }^{5}$ En 1920, Detroit era la cuarta ciudad de Estados Unidos. En las tres primeras (Nueva York, Chicago y Philadelphia) la construcción de la red de metro en superficie había comenzado a finales del siglo XIX. Los informes de varias comisiones de Detroit revelan ya esta necesidad en los años diez, pero nunca se llegó a construir. Detroit City Plan and Improvement Commission, 1914

${ }^{6}$ Para profundizar en las vinculaciones entre desarrollo urbano y estructura de comunicaciones, vid $\mathrm{R}$
} 
transporte público o de los servicios básicos, parecen apuntar que, ya desde comienzos del siglo XX, los modos de desarrollo de Detroit no sólo estuvieron vinculados a las transformaciones económicas, sino también a una toma de decisiones política que apoyó el modelo dominante.

El estudio de los planes urbanísticos de esta etapa en Detroit y la comparación con los desarrollados en otras metrópolis americanas ${ }^{7}$ permite comprender que en Detroit no fue únicamente la desregulación la que permitió que se impusiera un modelo desigual, sino la combinación de una planificación sectorial que sustentó los modos de producción del espacio del capitalismo industrial junto a la ausencia de regulación del modelo urbano en su conjunto. Ante la falta de un plan global, se impusieron las decisiones de una planificación sectorial y fragmentada. El plan de carreteras hizo accesible gran parte de la periferia e impulsó el modelo de crecimiento en extensión de baja densidad. La regulación de usos del suelo urbano no logró mejorar las condiciones del centro pero sí definió los barrios residenciales periféricos como espacios idóneos para las clases medias-altas americanas de raza blanca y sustentó la configuración de áreas industriales lineales a lo largo de la red de ferrocarril que coincidían con las necesidades de los nuevos procesos de producción (pero no con las de toda la industria de Detroit). Asimismo, la ausencia de un modelo urbano de conjunto y de un control sobre los modos de producción del espacio en una ciudad en constante desarrollo hizo posible que el proceso de crecimiento se manifestase de manera profundamente desigual en las siguientes décadas. Sin mecanismos de reequilibrio de las desigualdades generadas por el nuevo modelo productivo, Detroit continuó creciendo siguiendo un patrón basado en una diferenciación espacial y una segregación social cada vez más profundas.

\section{DETROIT EN LOS AÑOS DE LA DEPRESIÓN. ESPECIALIZACIÓN PRODUCTIVA Y TANSFORMACIÓN URBANA}

La Depresión de 1929 supuso un punto de ruptura en el proceso continuo de crecimiento de Detroit. En los años veinte, la industria siguió su (aparentemente) imparable desarrollo y los trabajadores inmigrantes continuaron acudiendo a la ciudad. La población aumentó en casi seiscientos mil habitantes en diez años y las dinámicas de diferenciación espacial se aceleraron. La principal transformación económica fue

\footnotetext{
${ }^{7}$ Los primeros planes de sistemas de parques americanos planteados por Frederick Olmsted datan de finales del siglo XIX. El plan de la Senate Park Commission de Washington fue iniciado en 1901, el Plan de Chicago de Daniel Burnham y Edward H. Bennett aprobado en 1909. E Plan regional de Nueva York de la Regional Plan Association se aprobó en 1929. Todos constituyen ejemplos de planes de conjunto vinculados al gobierno de la nueva metrópolis industrial. En Detroit, la planificación urbana se distinguió por su carácter sectorial. A lo largo de las primeras décadas de siglo se plantearon planes de carreteras y regulaciones de usos del suelo pero ningún plan global que planteara un modelo de desarrollo de la ciudad. Para una visión general vid. Mancuso, 1980; Sutcliffe, 1981
} 
que el sector del automóvil se destacó cada vez más y Detroit se hizo progresivamente más dependiente de él ${ }^{8}$. Este dominio no se debió a un declive generalizado de los demás sectores, sino a que el espectacular desarrollo de la industria automovilística tendió a ocultar la diversidad productiva de la ciudad.

Figura 4. Localización de la industria de Detroit por sectores (1940).

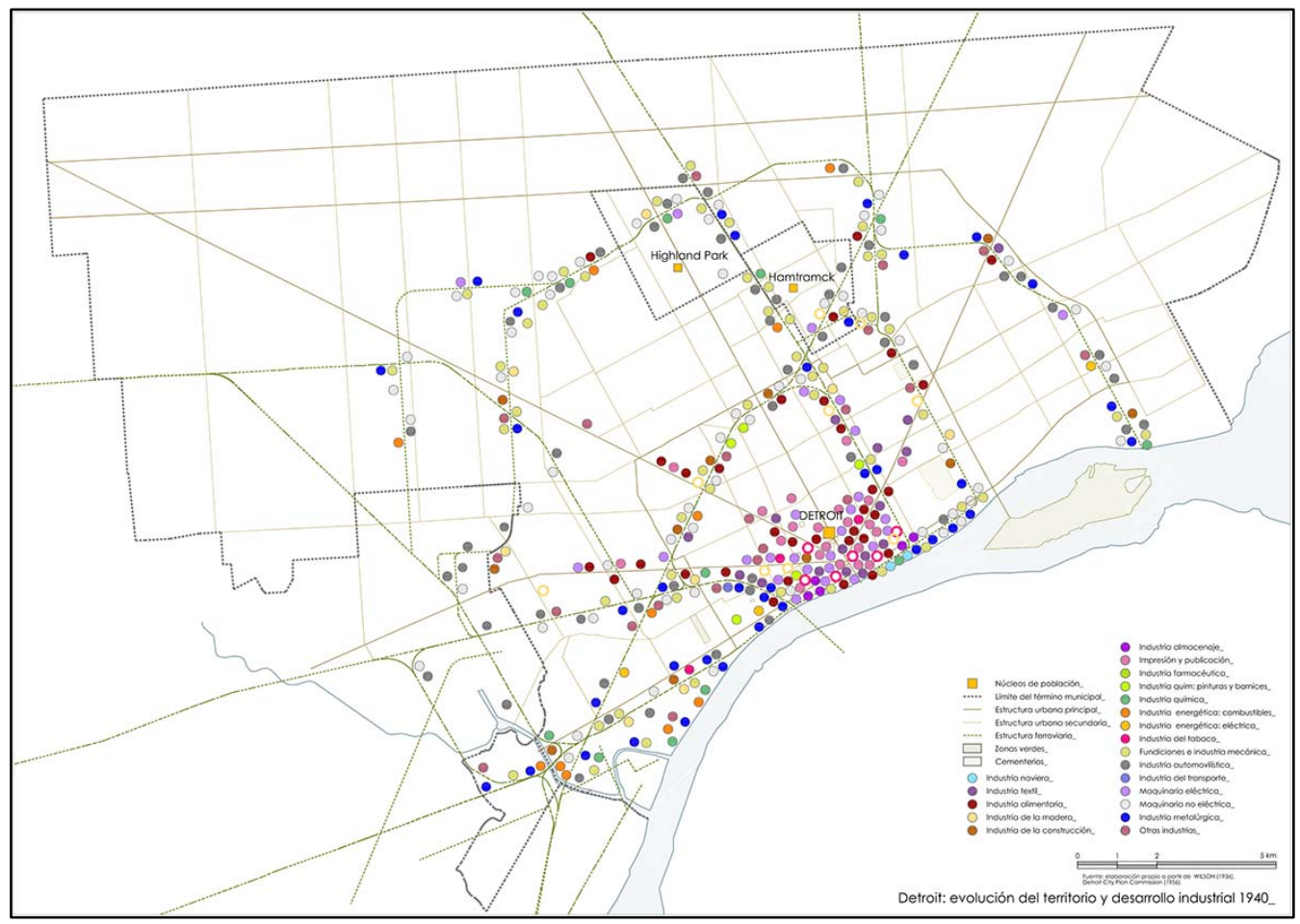

Fuente: Elaboración propia.

En este contexto de crecimiento acelerado, la Depresión tuvo un impacto extraordinario. El consumo se redujo por efecto de la crisis y los sectores más afectados fueron los de los bienes de consumo; sobre todo, la industria

${ }^{8}$ En 1930, casi la mitad de los obreros trabajaban en la industria automovilística y el valor de sus productos superaba ya el $50 \%$ del total (U.S Bureau of the Census. $15^{\text {th }}$ Census of the United States - 1930.). El nivel de especialización era notable para una ciudad de su dimensión. En otras ciudades similares, como Chicago, Philadelphia o Pittsburgh, las cifras apenas alcanzaban el 30\% (Davis, 1988). 
automovilística. Muchas empresas del sector quebraron o fueron absorbidas por las grandes corporaciones, acelerándose la construcción de una estructura de oligopolio ${ }^{9}$. Cuando Detroit se recuperó de la crisis, ya no era sólo una ciudad especializada y, por tanto, vulnerable a las fluctuaciones del sector dominante, sino que una buena parte de su economía dependía de las decisiones, conflictos y reestructuraciones internas de las tres grandes empresas automovilísticas: Ford, General Motors y Chrysler.

La influencia en el gobierno de la ciudad de los Big Three también aumentó durante la crisis. El municipio de Detroit no podía afrontar el incremento de los costes asistenciales derivados del aumento del desempleo y la disminución de los salarios, ya que estaba prácticamente arruinado debido a los costes de anexión de las últimas décadas. El Ayuntamiento se apoyó en los préstamos de las élites empresariales para cubrir parte de estos costes, lo que, a largo plazo, hizo más dependiente a la ciudad de las grandes empresas automovilísticas.

Los dos patrones espaciales de localización industrial continuaron pero la crisis hizo subrayó sus diferencias. El sector textil, el alimentario, la impresión y publicación o la fabricación de maquinaria eléctrica mantuvieron su ubicación en el centro de Detroit. Por el contrario, las grandes empresas buscaron localizaciones próximas a la red de ferrocarril, alejándose cada vez más en función de la oportunidad de adquisición de los terrenos. Los sectores y empresas proveedoras de la industria automovilística siguieron las dinámicas de descentralización que, hasta entonces, sólo ésta había adoptado. La parte de la industria que económicamente más aportaba a la ciudad y daba mayor número de empleos comenzó a trasladarse masivamente fuera del término municipal ${ }^{10} \mathrm{y}$, a partir de la Depresión, la ciudad ya no pudo captar ese crecimiento mediante la anexión. Si bien la industria continuó creciendo hasta después de la Segunda Guerra Mundial, la dinámica de descentralización y la incapacidad del gobierno local por mantenerla en la ciudad se hicieron cada vez más patentes.

La Depresión afectó de forma radicalmente diferente a los distintos grupos sociales, intensificando las disparidades. La crisis fue especialmente grave para los

${ }^{9}$ Los inicios de la industria automovilística en Detroit se habían caracterizado por la diversidad de empresas y procesos de trabajo. A partir de la introducción de la producción en serie por parte de Ford y de las transformaciones empresariales de General Motors poco después, el dominio de las grandes corporaciones se hizo cada vez mayor. En 1911, Ford y General Motors producían el 38\% de los automóviles de Estados Unidos, una década más tarde el 60\% y en 1930, los Big Three (Ford, General Motors y Chrysler) controlaban entre el $80 \%$ y el $90 \%$ del mercado (Klepper, 2001).

${ }^{10}$ En 1929, un 25\% de los trabajadores de la industria automovilística de Estados Unidos trabajaban en Detroit, frente a un $10.4 \%$ en el resto de la Detroit Industrial Area. Diez años más tarde la proporción se había invertido: el $23.3 \%$ trabajaba en Detroit y un $24.8 \%$ en el área metropolitana (Detroit City Plan Commission, 1944). En los años 30, el número de empleados del sector en la ciudad de Detroit se redujo un 13\%, mientras que en el total del área metropolitana (incluido Detroit) aumentó un 24\% (U.S Bureau of the Census, 1930, 1940). 
obreros descualificados, que fueron los primeros en perder sus empleos. El impacto fue aún mayor en el caso de los trabajadores negros, ya que se añadió una creciente exclusión. A la discriminación racial en el espacio de trabajo (tanto por parte de los empresarios como de los trabajadores blancos que se oponían a que ocupasen los puestos de trabajo) se unió la segregación residencial que condujo a la concentración de la comunidad negra en el centro de Detroit, la zona peor dotada y con el parque inmobiliario más envejecido. La ausencia de intervención del gobierno local intensificó, a su vez, el deterioro del centro urbano.

El proceso de diferenciación espacial que se había iniciado a finales de la década de 1910 evolucionó así hacia un modelo especializado por uso y segregado por clase y raza. Esta división del espacio se extendió también a un área metropolitana en expansión. El centro urbano y los municipios industriales de la periferia sufrieron procesos continuados de disminución de la actividad económica, estancamiento o descenso de población y concentración de las rentas bajas. Por el contrario, la red de carreteras favoreció la salida de las élites urbanas que aprovecharon la crisis del mercado inmobiliario para trasladarse a los suburbios y alejarse de todo aquello que la ciudad comenzaba a simbolizar: el declive, la crisis y el conflicto social y racial.

\section{CRECIMIENTO ECONÓMICO Y ESPECIALIZADIÓN: LA CONSTRUCCIÓN DEL ÁREA METROPOLITANA DE DETROIR TRAS LA SEGUNDA GUERRA MUNDIAL}

La recuperación económica de Detroit estuvo vinculada a la reconversión de la industria estadounidense para la producción de guerra, en la que el sector automovilístico fue el principal implicado. Detroit, la ciudad del automóvil, pronto se convirtió en el Arsenal de la democracia (Sugrue, 1996)

A partir del ataque a Pearl Harbor en 1941, se suspendió la fabricación de automóviles y el gobierno federal otorgó financiación a las empresas del sector para la construcción de nuevas plantas. Las directrices federales, que obligaban a adoptar ubicaciones periféricas para limitar los daños en caso de bombardeo, impulsaron la dinámica de descentralización, asegurando además la construcción de la red de comunicaciones necesaria. Las nuevas fábricas automovilísticas sentaron un patrón espacial descentralizado y disperso que se acentuó durante las siguientes décadas. Las transformaciones tecnológicas de la industria del automóvil permitían la fragmentación de los procesos de trabajo y la construcción de centros especializados en la periferia. El principal problema era el incremento de las necesidades de transporte, pero éstas fueron paliadas primero por las carreteras construidas durante la guerra para asegurar el acceso a las fábricas de armamento y, más tarde, por los planes y programas federales de construcción de autopistas. Entre 1947 y 1955, se abrieron veinte nuevas fábricas de los Big Three en el área metropolitana de Detroit (Fainstein et Al, 1983). Su localización dependía casi exclusivamente de la disponibilidad de suelo a bajo coste y de las condiciones de accesibilidad, pero las 
ventajas fiscales ofrecidas por los municipios de la periferia también influyeron en las decisiones de las empresas Detroit City Plan Commission, 1956).

El incremento de la producción armamentística impulsó un crecimiento excepcional en Detroit y en la periferia, pero el final de la guerra marcó un punto de inflexión. A partir de entonces, la proporción de la industria situada en el municipio de Detroit respecto al total del área metropolitana comenzó un descenso que se ha prolongado hasta hoy.

Cuadro 2. Proporción de la industria de Detroit respecto al total del área metropolitana.

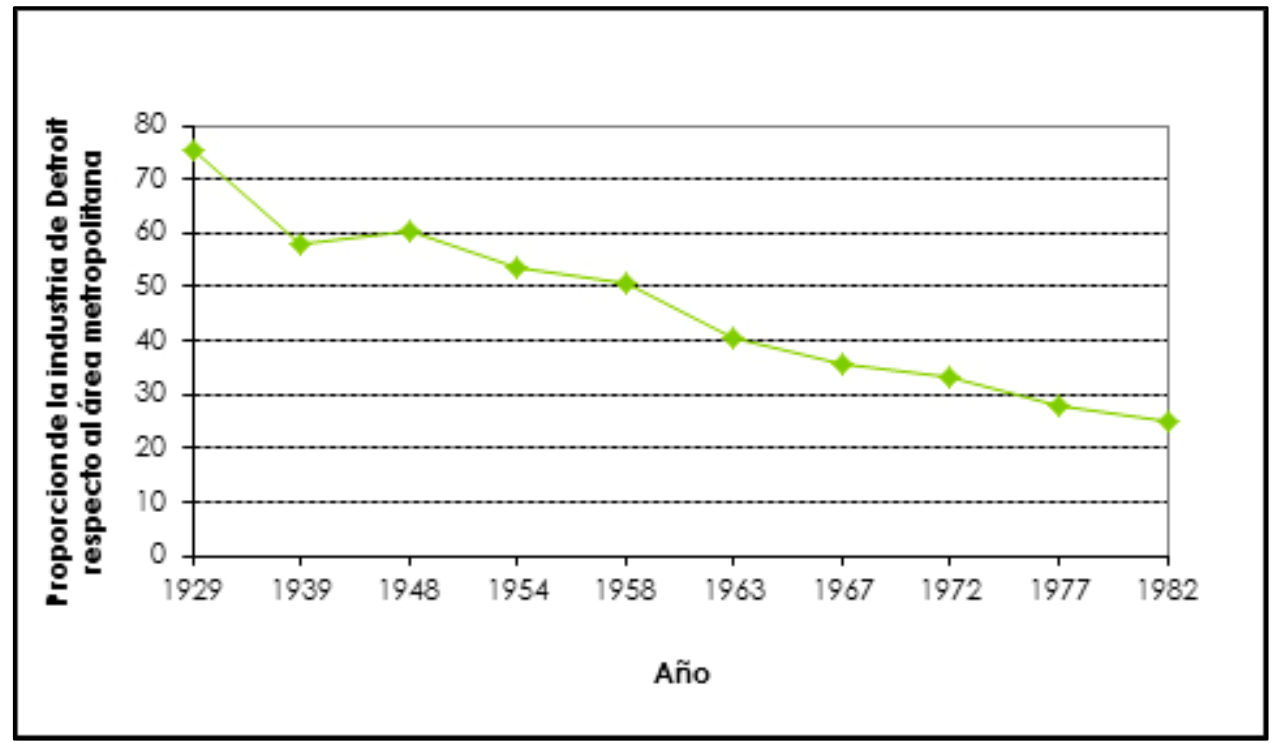

Fuente: elaboración propia a partir de Darden et Al, 1987. Tabla 2.1

Aunque parte de la industria siguió las dinámicas descentralizadoras del sector automovilístico, también fueron muchas las empresas que permanecieron en Detroit. Éstas eran, en muchos casos, empresas de menor dimensión o capacidad productiva, pero muy arraigadas a la ciudad y que constituían una parte importante de su base económica. Frente a la visión más extendida de que, tras la guerra, Detroit se vinculaba sólo a la industria automovilística, las estadísticas revelan que aunque era una ciudad fuertemente especializada, aún resistía parte de su compleja estructura productiva $^{11}$. La industria alimentaria, la maquinaria o la impresión y publicación

${ }^{11}$ Una encuesta sobre la actividad industrial realizada en 1953 (Detroit City Plan Commission, 1956) nos permitió reconstruir la realidad productiva completa de la ciudad en aquella época y revelar el papel de la planificación urbana de posguerra en la transformación progresiva de una ciudad compleja y resistente en un soporte espacial especializado y frágil. Fernández Águeda, 2012 
experimentaron un fuerte desarrollo en las décadas de postguerra, pero el extraordinario crecimiento del sector automovilístico pareció ocultar esta otra realidad productiva.

El discurso institucional tendió a enfatizar aún más la dominancia del sector automovilístico y a vincular el futuro de la ciudad con el devenir de su principal industria. Para los poderes locales, como para el resto de Estados Unidos, "Detroit exists primarily to put the nation on wheels" (Detroit City Plan Commission, 1944a: 5). A pesar de que las estadísticas prueben lo contrario ${ }^{12}$, los informes de la Detroit City Plan Commission afirmaban en 1944 que "las viejas industrias no relacionadas con la producción automovilística han entrado en declive o desaparecido" (Detroit City Plan Commission, 1944a, p.6). Esta visión determinó las políticas locales de las siguientes décadas, que destinaron la mayor parte de los esfuerzos y recursos a construir un soporte espacial para impedir la huida de la industria automovilística.

Sin embargo, la ciudad difícilmente podía competir con la periferia. Los reducidos costes de los terrenos, las exenciones fiscales de los municipios suburbanos y la nueva red de comunicaciones, convertían a la periferia en el espacio idóneo para el desarrollo de los nuevos procesos de trabajo de la industria. Las décadas de postguerra se caracterizaron por un intenso proceso de competencia entre los municipios del área metropolitana por captar el potencial industrial y por unas políticas locales que acentuaron, por una parte, la especialización y dependencia del territorio y, por otra, la producción de un espacio segregado por clase y por raza. Se tratará, a continuación, de revelar las conexiones entre transformaciones productivas, modos de gobierno local y la evolución del área metropolitana de Detroit en las décadas de postguerra.

\subsection{SEGREGACIÓN Y CONFLICTO: EL PAPEL DE LA PLANIFICACIÓN URBANA}

El incremento de la producción y la movilización de hombres al frente provocaron, por primera vez en la historia de Detroit, un problema de falta de mano de obra, que se atenuó gracias a la inmigración negra proveniente del sur. Hasta entonces relegados a la agricultura y los servicios, la guerra dio acceso a los trabajadores

\footnotetext{
${ }^{12}$ La comparación entre el Censo de 1940 (U.S. Bureau of the Census, 1940) y la encuesta industrial realizada por la Detroit City Plan Commission en 1953 (Detroit City Plan Commission, 1956) refleja que algunas de estas antiguas industrias experimentaron, en realidad, un fuerte crecimiento en este período. Si bien existió un proceso general de concentración horizontal y disminución del número de fábricas que puede llevar a la conclusión errónea de que estos sectores habían entrado en declive, el número de empleados y el valor de sus productos se incrementó de forma notable. La industria alimentaria empleaba en 1953 un 85\% más de obreros que en la década anterior, mientras que la impresión y publicación y la industria del mueble aumentaron sus efectivos más del cincuenta por ciento (U.S. Bureau of the Census, 1940; Detroit City Plan Commission, 1956).
} 
negros al empleo industrial, pero no alteró las prácticas discriminatorias. La industria automovilística les ofreció empleo, pero ocuparon los trabajos más duros y fueron el grupo más vulnerable a los despidos. La discriminación en las fábricas no sólo vino de parte de los empresarios, sino también de los trabajadores blancos que los excluyeron de sus estructuras de aprendizaje y formación (Sugrue, 1996)

Su principal problema en Detroit fue, no obstante, el acceso a la vivienda. Gran parte de los municipios suburbanos e incluso algunos barrios de la periferia de Detroit habitados por clases medias impusieron restricciones al asentamiento de población negra $^{13}$. Aunque la ciudad contaba con un parque de viviendas en propiedad al que parte de la clase obrera podía acceder, los negros fueron discriminados por el mercado inmobiliario privado que preveía un descenso del valor de las propiedades y de las ventas entre los blancos, en caso de admitirlos. Los trabajadores negros se vieron, así, confinados al centro urbano, cuya densidad continuó incrementándose y que pronto se convirtió en el modelo del gueto definido por la escuela de Chicago (Park, Burgess y McKenzie, 1925). A pesar de las evidentes prácticas discriminatorias y la reducida estructura de oportunidades, para la mayor parte de la población blanca, la pobreza y el hacinamiento del gueto de Detroit no eran consecuencia de un modelo desigual, sino de unos modos de vida que justificaban la segregación (Sugrue, 1996: 9).

Los programas federales de apoyo a la compra de vivienda tampoco resultaron de ayuda para la comunidad negra. El National Housing Act había creado, en 1934, la Federal Housing Administration, con el objetivo de incentivar la construcción y la compra de vivienda tras la Depresión. La agencia federal estableció apoyos al sistema hipotecario mediante préstamos a largo plazo y bajo interés, que debían permitir a las clases obreras acceder a la compra de vivienda. Sin embargo, la asignación de la financiación fue arbitraria y desigual. En primer lugar, dio prioridad a las operaciones consideradas de menor riesgo, es decir, a la adquisición de vivienda suburbana en barrios social y racialmente homogéneos. Por el contrario, la compra en los centros urbanos quedó excluida, al igual que las ayudas para el alquiler y la rehabilitación. En segundo lugar, los negros fueron, primero de forma oficial y después oficiosa, excluidos de las ayudas. Los programas federales costearon así fundamentalmente, la compra de vivienda suburbana de las clases medias y trabajadoras blancas (Beauregard, 2006; Thomas, 1997).

${ }^{13}$ En 1940, Dearborn contaba con 64.000 habitantes de los que sólo 35 eran negros. En la posguerra "se convirtió en un símbolo, conocido en toda la nación, de la hostilidad de los desarrollos suburbanos hacia los negros” (Farley, Danzinger y Holzer, 2000, p.156). Warren, cuya población era mayoritariamente de clase trabajadora blanca, ha sido considerada como un "refugio para las clases obreras blancas atemorizadas" por sus medidas discriminatorias (Darden et Al., 1987, p.97) 
Figura 5. Densidad de población por secciones censales.

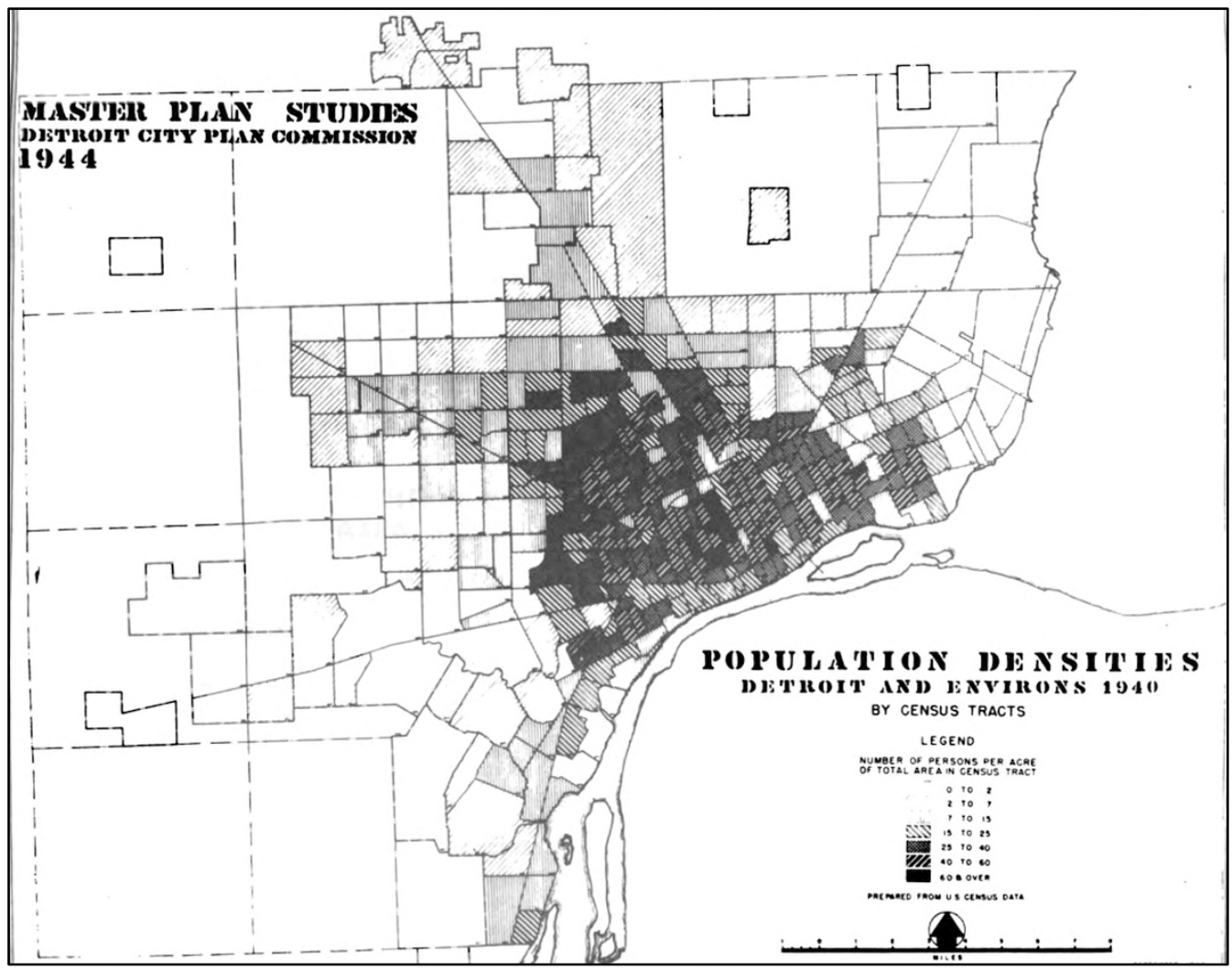

Fuente: Detroit City Plan Commission, 1946a.

Si la compra resultó impensable para la mayor parte de las familias negras de Detroit, la oferta de alquiler era reducida y costosa. Los desarrollos de baja densidad y vivienda unifamiliar estaban fundamentalmente destinados a la compra y el mercado de alquiler estaba constituido por las viviendas más antiguas y deterioradas, subdivididas y a precios abusivos, que los trabajadores negros se veían obligados a aceptar ante la falta de alternativas. La Detroit City Plan Commission estimaba que, en 1940, había 70.000 infraviviendas en Detroit, la mayoría de ellas situadas en el centro y ocupadas por población negra (Thomas, 1997). Dichas viviendas se encontraban en barrios "de alto riesgo" y, por tanto, descartados de las ayudas 
públicas para la compra de vivienda ${ }^{14}$. Los planos de las agencias federales fueron la base sobre la que se apoyaron las entidades bancarias para definir la concesión de préstamos a la rehabilitación, por lo que también quedaron, en general, excluidas de estos. Se estima que, en 1947, de las 545.000 viviendas disponibles en el área metropolitana de Detroit sólo el 7.4\% estaban disponibles para trabajadores negros y menos del 1\% de las 186.000 viviendas construidas en los años 40 admitieron población negra (Sugrue, 1996).

Los programas de vivienda pública de iniciativa municipal fueron casi inexistentes durante la guerra. Aunque, entre 1941 y 1944, la demanda ascendía sólo en Detroit a 10.000 viviendas, se construyeron menos de 2.000 viviendas públicas y menos de doscientas privadas para los inmigrantes negros de Detroit, que se vieron obligados a hacinarse en el centro. En una ciudad en general poco densa, en la que dos terceras partes de su parque inmobiliario eran viviendas unifamiliares, más del $27 \%$ de los hogares negros tenían más de una persona por habitación y la media era de 4.6 personas por vivienda (frente a las 3.8 de los hogares blancos) (Sugrue, 1996: 42).

Tras la guerra, el área metropolitana de Detroit era ya un territorio fuertemente segregado las políticas públicas locales contribuyeron de forma decisiva a acentuar las desigualdades. No sólo fue la ausencia de programas de vivienda pública (que diferenciaba a Detroit de otras grandes ciudades americanas), sino que la renuncia continuada a construir un sistema de transporte público ${ }^{15}$, unida a la creciente descentralización de la industria, limitó el acceso al empleo de los trabajadores que no podían acceder a la compra de un automóvil privado.

Por otro lado, la falta de inversión de recursos en el centro urbano y las limitaciones evidentes de unos servicios básicos que continuaron sin reforzarse, contribuyó al deterioro progresivo de la zona más antigua de la ciudad, aquella que contaba con un parque inmobiliario más envejecido y cuyos espacios públicos necesitaban una rehabilitación urgente. La construcción del gueto de Detroit tras la Segunda Guerra Mundial parece alejarse, en este sentido, de los procesos "naturales" de sucesión - invasión enunciados por la escuela de Chicago. El deterioro del centro parece, en cambio, fuertemente vinculado tanto a las prácticas discriminatorias del

\footnotetext{
${ }^{14}$ La Home Owners' Loan Corporation, elaboró los Residential Security Maps and Surveys, planos que dividían las áreas metropolitanas de las principales ciudades de Estados Unidos en zonas clasificadas de la A (verde) a la D (rojo) a partir de una encuesta sobre la antigüedad de las edificaciones, el estado de conservación y los servicios del barrio. Las zonas C y D y sus residentes quedaron excluidos de todas las ayudas, en una práctica posteriormente conocida como redlining. Todos los barrios con alguna pequeña zona de vivienda negra en Detroit fueron marcados como D, mientras que los barrios blancos con normativas discriminatorias se incluyeron entre las mejor valoradas (Sugrue, 1996, p.43-47).

${ }^{15}$ Tras la Segunda Guerra Mundial, Detroit tenía 1.849.568 habitantes y el área metropolitana superaba los tres millones. Sin embargo, aún no contaba con una red de metro, mientras las principales ciudades americanas hacía décadas que lo habían construido. En una encuesta sobre el nivel de satisfacción de los habitantes, tan sólo un $2 \%$ se mostró satisfecho con el transporte público (Kornhauser, 1952)
} 
mercado inmobiliario privado y de los programas federales, que limitaron la inversión de los propietarios en la conservación y rehabilitación del parque inmobiliario, como a unas políticas locales que apenas destinaron recursos al centro urbano.

Este modelo espacial polarizado, con diferencias crecientes entre centro y periferia, era la materialización de un orden social profundamente enraizado en la sociedad norteamericana que históricamente había manifestado una "profunda ambivalencia" por el hecho urbano, un rechazo por la ciudad entendida como foco de perversión y corrupción. Robert Beauregard reveló en qué medida el desarrollo del modelo suburbano y el declive de las ciudades industriales americanas tras la Segunda Guerra Mundial fueron, en realidad, las dos caras del mismo fenómeno (beauregard, 2006). La concentración de recursos en el crecimiento suburbano, materialización de un nuevo modo de vida que priorizaba el consumo frente a la producción y sobre el que se asentó la prosperidad económica de Estados Unidos tras la Segunda Guerra Mundial, sólo fue posible gracias a la falta de inversión en los centros urbanos. En este sentido, el declive de las antiguas ciudades industriales no se comprendió sólo como un efecto colateral del crecimiento, sino como un símbolo de progreso y una necesidad para la prosperidad de la nación.

La influencia de las políticas federales de posguerra en el desarrollo del modelo suburbano y el declive de la ciudad central ha sido analizada en numerosas ocasiones (Beauregard, 2001; Thomas, 1997). Todas las fuentes coinciden en que los dos pilares fundamentales fueron el apoyo federal a la compra de vivienda, descrito anteriormente, y el programa de financiación de construcción de la red de autopistas. Ambos impulsaron, en las décadas de postguerra, un doble proceso de suburbanización residencial y descentralización de la industria que espacializó a escala metropolitana un modelo socialmente segregado $\mathrm{y}$ funcionalmente especializado. Si en décadas anteriores las élites urbanas habían abandonado Detroit por los municipios suburbanos, las clases medias siguieron su ejemplo desde los años 50 ayudadas por la financiación federal.

En 1956, el Federal Highway Act dispuso una subvención federal del 90\% para la construcción de un sistema interestatal de autopistas en Estados Unidos, pero el caso de Detroit fue singular porque existía un proyecto local de 1946 que se había iniciado en parte y que el programa federal permitió financiar completamente. El proyecto, proponía una nueva red arterial radial dentro del municipio, construida en zanja y con accesos restringidos, que se introducía hasta el centro urbano, dotando a las zonas industriales y al centro financiero de unas condiciones óptimas de accesibilidad. El objetivo era resolver los dos que se consideraba los problemas más graves: el tráfico y la degradación. Como subrayaba un documento de la Detroit City Plan Commission: "Blight's fungus-like growth menaces the entire city" (Detroit City Plan Commission, 1944b: 4). El programa de autopistas parecía la ocasión para intervenir en la ciudad, impedir que el deterioro se extendiera y evitar la huida de las clases medias y las empresas. Paradójicamente, la nueva red arterial facilitó aún más su salida. 
Figura 6. Plan de red de autopistas. El plano muestra la relación de la nueva red arterial con las principales zonas industriales y con el centro financiero.

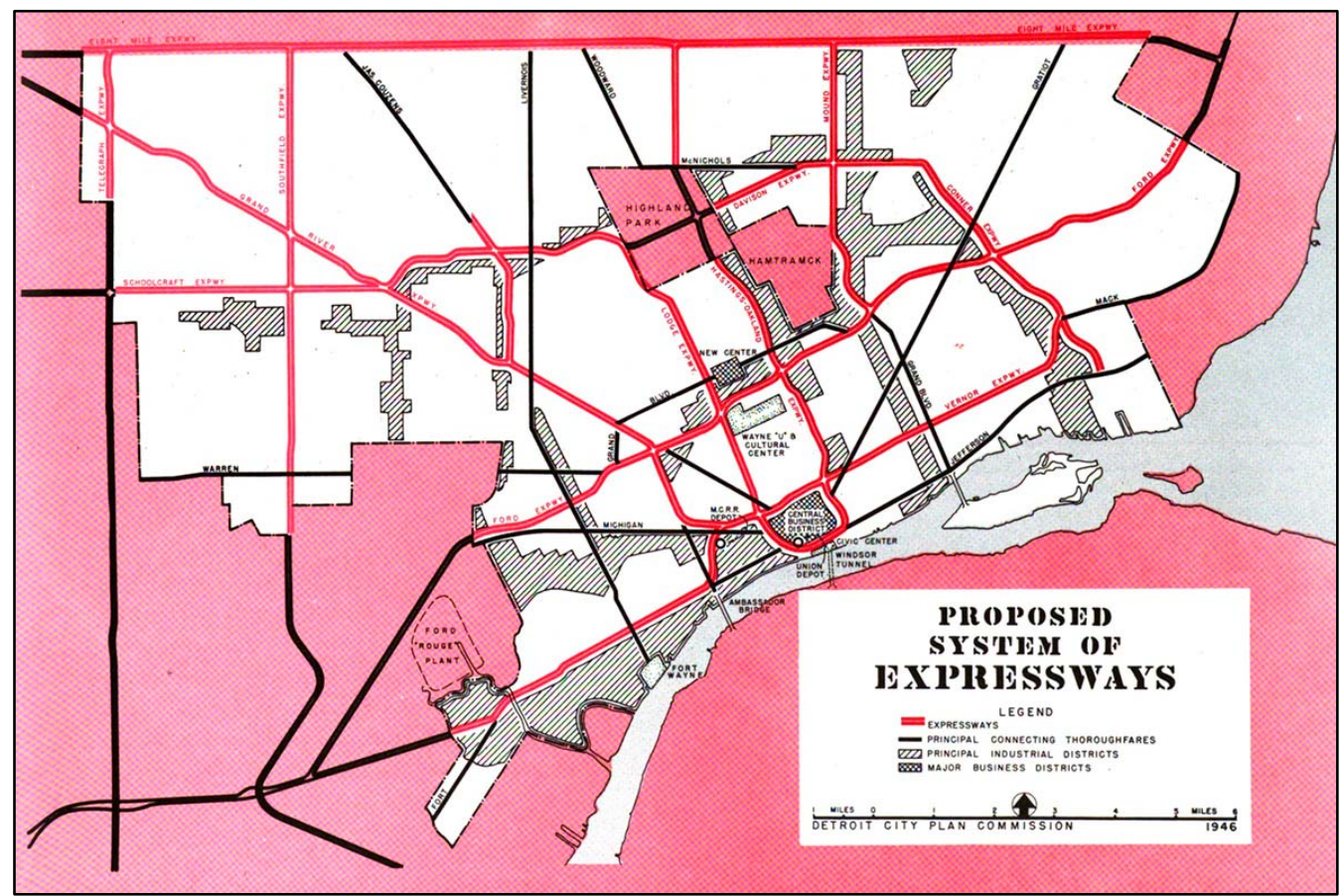

Fuente: Detroit City Plan Commission, 1946.

El impacto de las autopistas sobre la trama urbana de Detroit fue excepcional ya que constituyeron barreras en la trama urbana. $\mathrm{Si}$, por un lado, permitieron separar el centro financiero de las áreas degradadas del entorno, también dividieron barrios tradicionales fuertemente cohesionados. El trazado fue causa de conflicto, ya que los fines de reforma y racionalidad del plan hicieron coincidir las carreteras con las zonas más deterioradas y densas de la ciudad. Las zonas que no se vieron afectadas materialmente por las nuevas autopistas quedaron casi incomunicadas y se convirtieron en focos de degradación. En ausencia de programas de realojo, la comunidad negra tuvo también que afrontar la destrucción de parte de sus barrios (Thomas, 1997).

El declive del centro también planteaba un problema económico-fiscal, ya que gran parte de la recaudación municipal dependía del impuesto sobre la propiedad, calculado en función del valor de tasación de las edificaciones, que disminuía con su antigüedad. La Detroit City Plan Commission definió un extenso programa de renovación urbana en el que el grado de deterioro y el orden de prioridad de las operaciones era evaluado en función de la antigüedad de su parque inmobiliario (Detroit City Plan Commission, 1962: 2). Los proyectos fueron financiados por los fondos federales destinados a la renovación urbana pero la prioridad, el programa y la 
finalidad de las actuaciones los fijó el gobierno local. El objetivo era demoler totalmente las áreas degradadas para crear nuevas zonas residenciales "modernas y eficientes". Los proyectos no contemplaban el realojo y estaban destinados, en cambio, a fijar población de clase media en la ciudad. Las consecuencias fueron, una vez más, especialmente graves para la comunidad negra de Detroit, ya que los programas de renovación urbana acentuaron la falta de viviendas disponibles. Si bien a partir de finales de los años 60 los planes de renovación urbana comenzaron a incorporar programas de realojo, para entonces, los proyectos del centro ya habían sido aprobados y los habitantes desplazados de sus hogares.

Figura 7. Delimitación de las áreas degradadas a renovar.

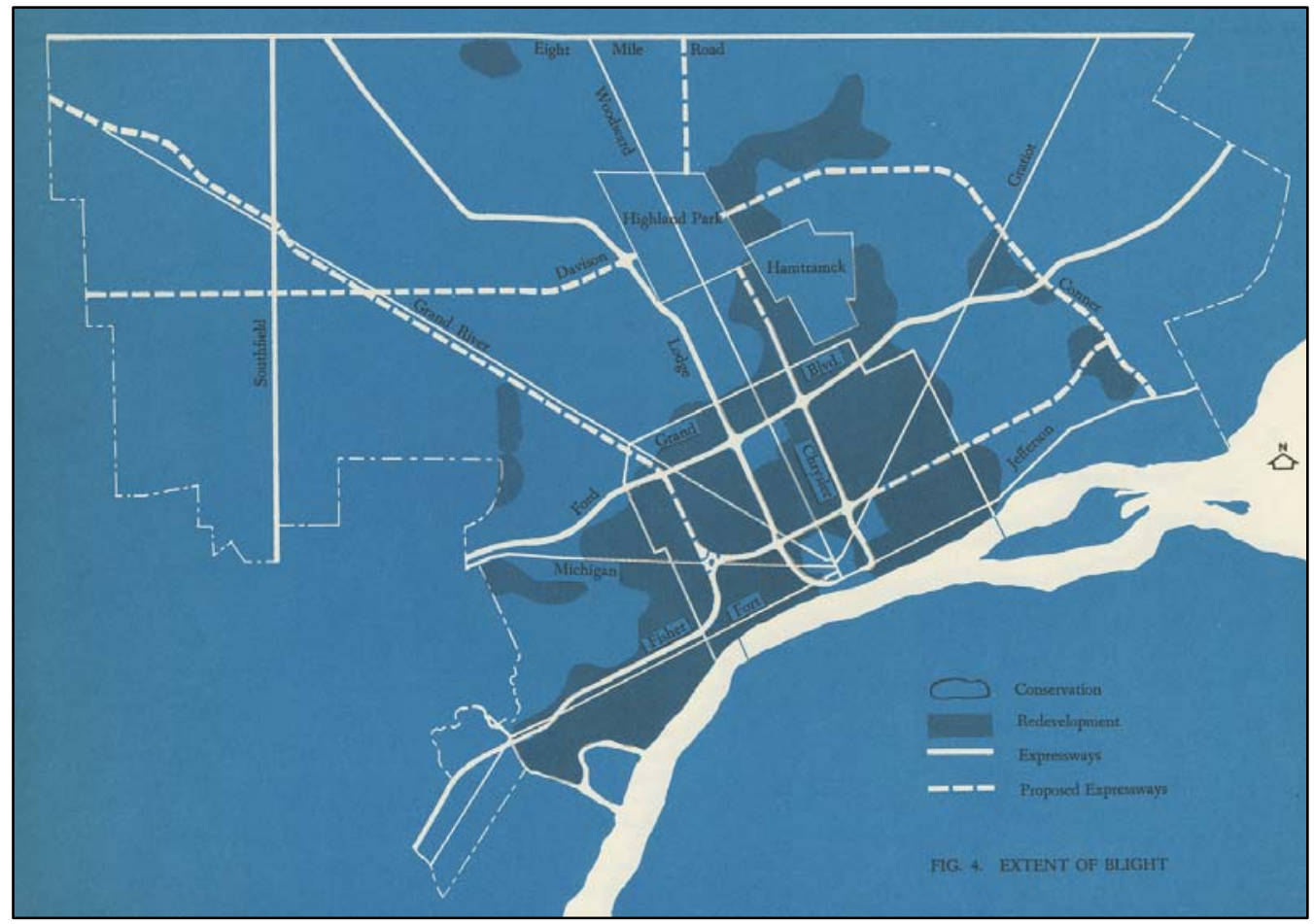

Fuente: Detroit City Plan Commission, 1962.

Los planes y proyectos de postguerra del ayuntamiento de Detroit, al igual que los programas federales, contribuyeron así a materializar un modelo desigual y segregado. Las revueltas urbanas de Detroit de 1967, que todavía hoy siguen siendo un hito en la 
historia de Estados Unidos, no fueron sino el estallido de un conflicto patente desde hacía décadas ${ }^{16}$.

\section{DESARROLLO DESIGUAL Y DECLIVE DE LA CIUDAD.}

Las revueltas urbanas transformaron la imagen de Detroit en el imaginario de la nación y la ciudad comenzó a identificarse con la pobreza, la degradación y las luchas raciales. El “Arsenal de la democracia” había devenido espacio de conflicto.

En 1950, Detroit alcanzó su máxima población histórica, 1.849.586 habitantes; a partir de entonces, la ciudad comenzó a decrecer. En las siguientes dos décadas, mientras la economía americana, la industria automovilística y el área metropolitana se encontraban en plena expansión, Detroit perdió más de trescientos mil habitantes. La crisis de los años 70 agravó las dinámicas existentes, la emigración se intensificó y, en esa década, Detroit perdió trescientos mil habitantes más. Por el contrario, la periferia continuó creciendo, aunque a un ritmo atenuado (Cuadro 3).

Cuadro 3. Evolución de la población de Detroit y del área metropolitana (1950 - 2010).

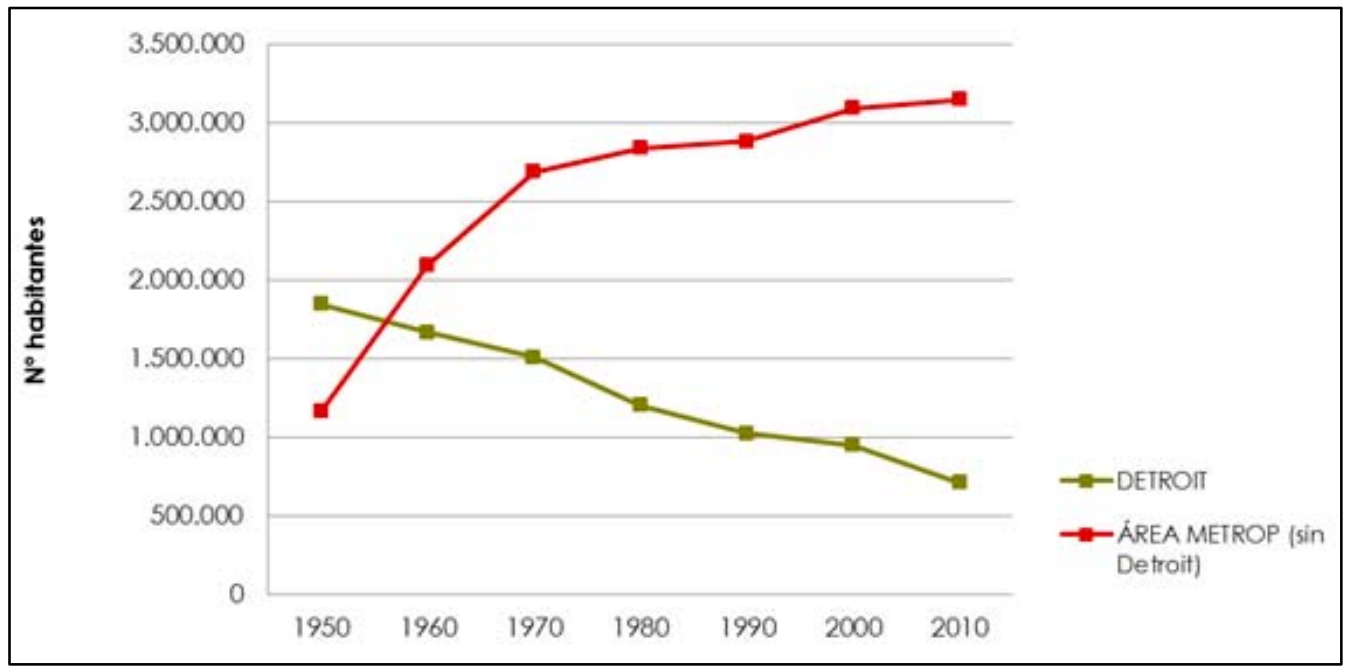

Fuente: Elaboración propia.

Sin embargo, la circunstancia más grave no fue la pérdida de población, sino el deterioro urbano y social del que ésta estuvo acompañada. Las disparidades entre centro y periferia continuaron incrementándose en las siguientes décadas.

\footnotetext{
${ }^{16}$ Los disturbios enfrentaron a negros y blancos durante cinco días, con un resultado de cuarenta y tres muertos, más de cinco mil detenidos, 2.509 edificios quemados y daños por valor de cuarenta y ocho millones de dólares. Sugrue, 1996. Thomas, 1988
} 
Figura 8. Tasa de pobreza en los principales municipios del área metropolitana de Detroit (1969).

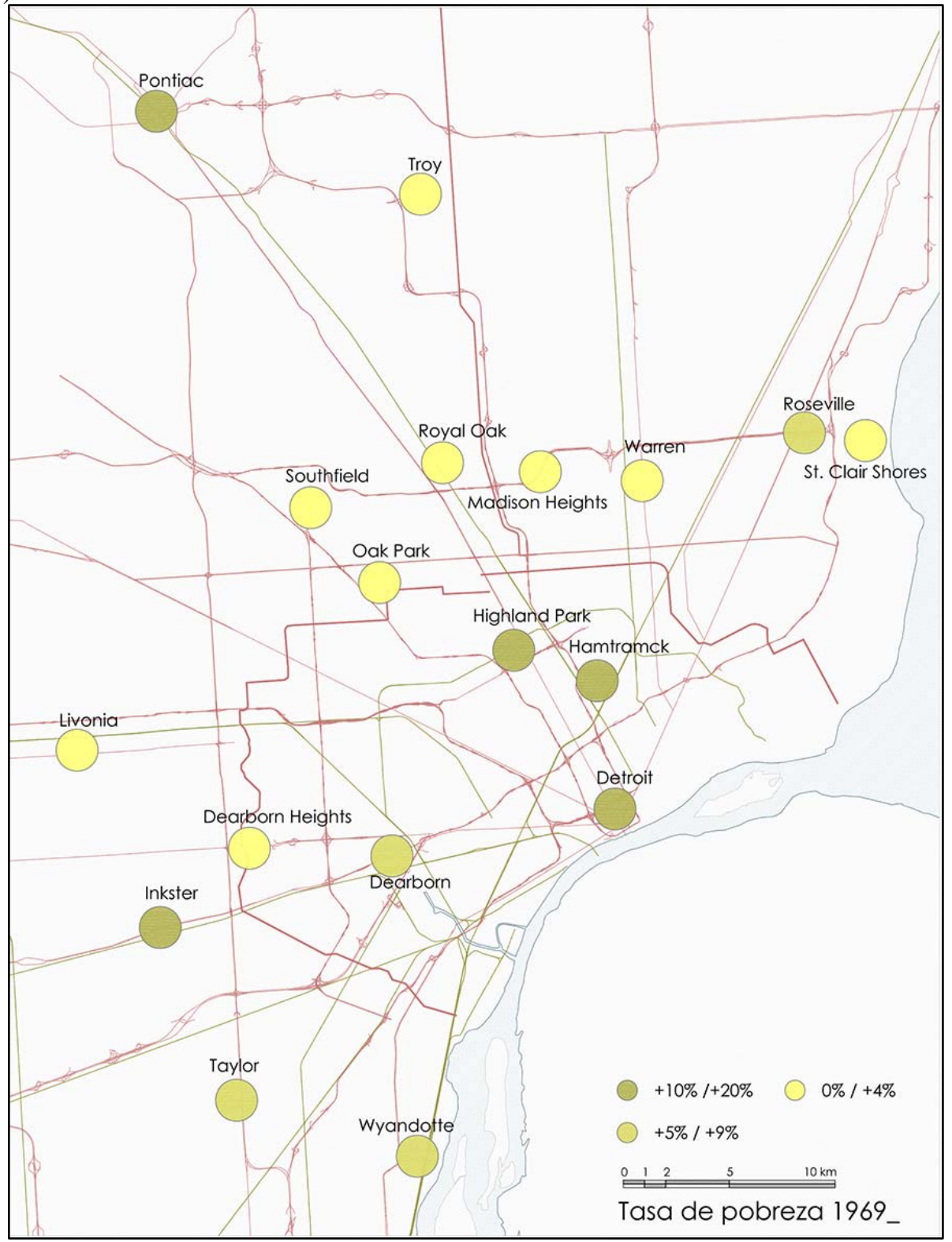

Fuente: Elaboración propia. 
Desde los años sesenta, la polarización se extendió al área metropolitana, manifestándose aún más las diferencias entre los polos de crecimiento (en municipios como Livonia, Southfield, Taylor y Troy) y los núcleos industriales en declive (Detroit, Hamtramck, Highland Park, Wyandotte y Pontiac). La crisis de Detroit, que había comenzado a finales de los 50 , en plena época de crecimiento, pronto se manifestó a través de todos los indicadores señalados en la literatura (aumento del desempleo y la pobreza, disminución de las rentas altas y habitantes con mayor nivel de estudios, aumento de viviendas vacantes y parcelas vacías etc.) y la acción pública no contribuyó a reequilibrar un modelo cada vez más desigual. A partir de las revueltas urbanas de 1967, la trayectoria de Detroit se convirtió en una espiral de decadencia de la que aún hoy no se ha conseguido recuperar.

En 1960, aún época de crecimiento y antes de las revueltas urbanas, la tasa de desempleo de Detroit era del $10 \%$, frente a algunos municipios de la periferia que apenas alcanzaban el 4\%. En 1969, antes de la crisis del petróleo, el 14,7\% de los habitantes de Detroit vivían bajo el umbral de la pobreza. En 1989, había aumentado al 32,4\% y en 2010, al 38,1\%. Las cifras resultan aún más graves cuando en algunos municipios de la periferia (Livonia o Troy) nunca se ha superado el $4 \%{ }^{17}$.

Cuadro 4. Evolución del número de industrias (1940 - 1992).

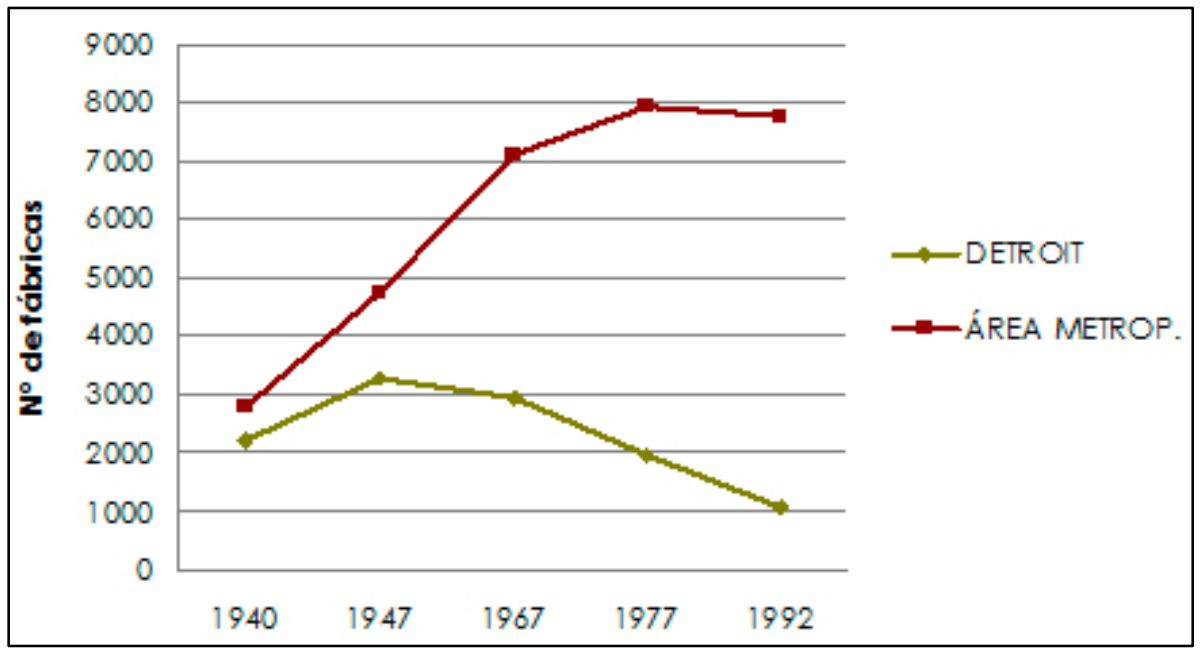

Fuente: Elaboración propia.

${ }^{17}$ Datos obtenidos del compendio de los County and City Data Books de 1944 a 2000, elaborado por University of Virginia Library. http://www2.lib.virginia.edu/ccdb/ 
Las revueltas urbanas acentuaron las dinámicas de traslado de la actividad económica, pero, frente a las hipótesis más extendidas, el éxodo había comenzado con anterioridad. Entre 1954 y 1977, el número de fábricas de Detroit descendió casi a la mitad, mientras que el terciario comercial y hostelero se redujo en más de diez mil establecimientos (U.S Bureau of the Census, 1954, 1977). La periferia experimentó la dinámica opuesta, ya que absorbió gran parte de esta actividad. A pesar de la incidencia de la crisis económica de los años 70 y del declive del sector automovilístico, la periferia de Detroit continuó su expansión. La reorganización global de la producción iniciada en los años 70 no determinó un declive de la industria del área metropolitana, donde la industria continuó creciendo, pero sí definió unas dinámicas cada vez más dispares.

De este modo, el análisis de la evolución de la ciudad revela que el declive había comenzado antes del inicio de la crisis del petróleo, vinculado al doble proceso de descentralización de la producción y suburbanización de la población. Las dinámicas externas (reorganización de la producción a escala global, incremento de la competencia y crisis de la industria automovilística americana) tuvieron, sin duda, un papel trascendental en el desarrollo de Detroit, pero estuvieron sostenidas por una acción pública que no contribuyó, al igual que en las décadas de postguerra, a paliar las consecuencias del modelo.

\subsection{EL GOBIERNO DE LA CIUDAD EN DECLIVE: EL CRECIMIENTO COMO OBJETIVO POLÍTICO}

En 1974, Coleman Young se convirtió en el primer alcalde negro de Detroit y su llegada suscitó esperanzas de regeneración social. Sin embargo, aunque implantó enérgicas políticas de igualdad racial, también adoptó posturas primero conciliadoras y luego poco transparentes con las élites empresariales. A medida que la crisis de la industria automovilística se acentuó, el modelo se aproximó al descrito por Friedrichs: cuando la industria dominante de una ciudad especializada entra en crisis, las élites económicas se asocian para mantener su influencia y aumentar la presión sobre la administración local (Friedrichs, 1993).

Durante el mandato del presidente Carter, Detroit percibió un importante incremento en los fondos federales, que el gobierno local empleó en el que se convirtió en el objetivo principal de la política municipal: la recuperación económica. A pesar del evidente deterioro de las condiciones de vida de los habitantes, la prioridad fue atraer a la actividad económica (principalmente a la industria automovilística), en detrimento de una población que cada vez recibía menos servicios y de una ciudad en la que se intensificaba el proceso de declive. Las subvenciones federales se destinaron en gran medida, a persuadir a las grandes empresas automovilísticas a invertir en operaciones inmobiliarias a través de ayudas directas o de la cesión de terrenos urbanizados y a atraer empresas mediante exenciones de impuestos (Orr y Stoker, 1994). La cara oculta de estas políticas de oferta fue el incremento de la carga impositiva a los hogares (Hill, 1983) 
Figura 9. Tasa de pobreza en los principales municipios del área metropolitana de Detroit (1989). La comparación con la figura anterior subraya el incremento de las disparidades.

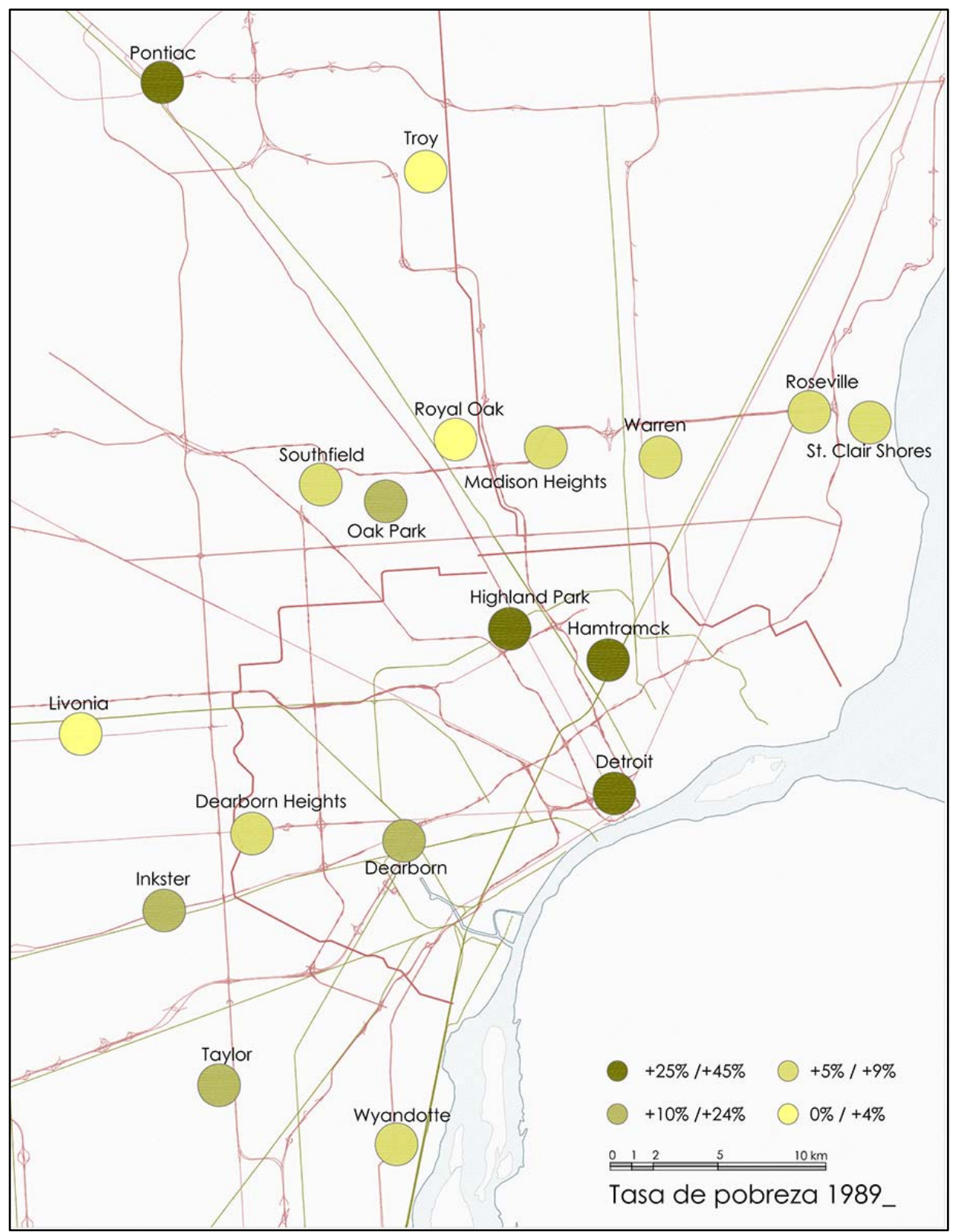

Fuente: Elaboración propia. 
A principios de los años 80, la crisis del sector automovilístico, la fuerte emigración y los recortes de la administración Reagan sumieron a Detroit en una profunda crisis fiscal. El ayuntamiento se apoyó en el sector privado, pero lo que comenzó como una asociación para promover la renovación urbana se convirtió, a lo largo de cinco mandatos, en una maquinaria política al servicio del alcalde Young. Estas décadas se caracterizaron por una interferencia cada vez mayor del capital privado y de las élites empresariales en el gobierno de la ciudad. Si hasta entonces, la planificación urbana había recaído en el sector público, Young anuló prácticamente las competencias de la Detroit City Plan Commission, para que la adjudicación de los proyectos recayera en la alcaldía (Digaetano y Lawless, 1999).

El fin de la comisión de planeamiento fue también el fin de la planificación global en una ciudad que, a partir de entonces, se desarrolló a través de proyectos parciales. El frente del río, abandonado por la industria, constituyó el terreno ideal para una serie de proyectos inmobiliarios aislados que no contribuyeron a revitalizar la ciudad. La destrucción de Poletown, uno de los barrios obreros históricos simboliza esta apuesta por la gran industria en detrimento de los ciudadanos. Cuando General Motors amenazó con cerrar sus plantas de la ciudad si no se le proporcionaba un terreno adecuado, el ayuntamiento le ofreció una gran parcela, urbanizada y con servicios, formada por unos terrenos abandonados por Chrysler años antes y por el barrio de Poletown, que fue expropiado por causa de utilidad pública a pesar de la fuerte oposición vecinal, el ayuntamiento

A finales de los años 80, el gobierno local empleó la financiación federal en la construcción del Detroit People Mover, una línea automática de tren ligero elevado, de recorrido circular en torno a un centro financiero cada vez más vacío. Por el contrario, continuó renunciando a la construcción de una red de transporte público eficaz que hubiera permitido conectar a la población con los principales centros de trabajo. El gobierno de Coleman Young terminó, en 1993, tras varios escándalos por corrupción. La ciudad y sus habitantes fueron los grandes perjudicados por veinte años de renuncia explícita al gobierno de la ciudad.

Los objetivos del siguiente alcalde, Dennis Archer, fueron restablecer la transparencia y la recuperación económica de Detroit, que para entonces estaba sumida en la crisis. El nuevo alcalde retomó el liderazgo público en la planificación urbana constituyendo un departamento de urbanismo cuya propuesta obtuvo un Empowerment Zone Grant ${ }^{18}$. Esto supuso, sin duda, un importante avance y también una fuerte aportación económica, pero en 1997 se comenzaron a elevar voces de protesta ante la falta de resultados. A medida que las prioridades del gobierno local y los fondos federales continuaron centrados en la renovación del centro y en la recuperación económica (en este caso, con la construcción de dos estadios y varios

\footnotetext{
${ }^{18}$ Ayudas federales concedidas por la administración Clinton para revitalizar las ciudades en declive, que exigían la participación ciudadana y el consenso entre habitantes, agentes políticos y actores económicos.
} 
casinos), se elevaron las críticas de las asociaciones de vecinos que reivindicaban la rehabilitación de sus barrios.

Durante los años noventa, las políticas federales de apoyo a las ciudades contribuyeron a atenuar levemente las tasas de pobreza y desempleo de Detroit y el éxodo de habitantes y empresas se ralentizó. Todo hacía esperar que esa tendencia continuara pero los datos del censo de 2010 alertaron a todo el país: Detroit había perdido casi 200.000 habitantes en diez años y el número de viviendas vacías se ha duplicado hasta casi alcanzar las 80.000. La tasa de pobreza se había elevado seis puntos en cuatro años (U.S Bureau of the Census, 2010). Tras décadas de crisis económica, la quiebra declarada en 2013, no fue, por tanto, una sorpresa.

Si bien las nuevas iniciativas y las prácticas emergentes (Gallagher, 2010) apuntan a un nuevo dinamismo en la ciudad, la gravedad de un declive que dura ya cinco décadas parece necesitar de soluciones a mayor escala y de una acción pública decidida.

\section{CONCLUSIONES}

El análisis de la evolución urbana de Detroit permite extraer importantes conclusiones para la investigación del declive urbano. En primer lugar, confirma la hipótesis de la relación directa entre paradigma productivo, modos de gobierno y modelo territorial. Si bien muchas ciudades industriales de Estados Unidos compartieron condiciones externa similares, la intensidad y duración del declive de Detroit tan sólo puede explicarse desde el contexto local. Estudiar la evolución de la ciudad permite comprender que el declive de Detroit comenzó en realidad durante el período de auge de la economía americana, años antes de la crisis de la industria automovilística. Inscribir el estudio del declive en el tiempo contribuye así a excluir una comprensión de éste como un fenómeno cíclico, irreversible y vinculado exclusivamente a dinámicas externas, para afirmar, la relevancia de las decisiones de escala local. Esta investigacion apunta a que la trayectoria específica de Detroit, crecimiento - especialización y auge - crisis, tan sólo puede por la continua interacción entre dinámicas globales y modelos de gobierno de la ciudad.

En una primera etapa, la ausencia de control sobre el modelo de desarrollo, hizo que éste quedara supeditado a una planificación sectorial que impuso una visión fragmentada. Posteriormente, la planificación urbana de posguerra impuso un modelo diseñado para entrar en competencia con la periferia que negaba la naturaleza histórica de la ciudad e ignoraba las dificultades de transformarla en la tabla rasa necesaria para reproducir el modelo suburbano. La toma de decisiones política apoyó a las dinámicas en curso en una especialización progresiva que condujo a un auge de la ciudad a corto plazo, pero también sentó las bases de su crisis posterior. La hipótesis de la desregulación, siempre asociada al modelo americano, parece también poder ser contestada a partir del ejemplo de Detroit, cuyo desarrollo y declive fue consecuencia de la superposición de lógicas sectoriales y de la concentración de recursos. 
A partir de los años 70, cuando la industria dominante entró en crisis, se puso de manifiesto que la ausencia de políticas urbanas constituye también una forma de gobierno. La negación de un declive ya patente, la apuesta por el crecimiento económico como modelo y la renuncia de la iniciativa pública a orientar el futuro de la ciudad favorecieron la puesta en marcha de las propuestas sectoriales de la iniciativa privada que intensificaron aún más un modelo desigual. La reducción progresiva de la diversidad de la base productiva y su creciente especialización contribuyeron no sólo a hacer a Detroit más vulnerable a las crisis sectoriales, sino también a disminuir su capacidad de recuperación cuando la industria dominante entró en crisis. La evidente interferencia del sector privado en los años 70 fue tan sólo el último capítulo de un proceso continuado de incremento del de las élites económicas en el gobierno de la ciudad.

La evolución de Detroit está así vinculada a la transformación progresiva de un territorio complejo, con una base económica resistente, en un soporte espacial especializado y extremadamente frágil. Cuando dicho modelo entró en crisis, Detroit no pudo adaptarse a la nueva realidad. En este sentido, el declive puede entenderse, en los términos de Kevin Lynch, como la pérdida de la capacidad de adaptación de la ciudad a unas nuevas circunstancias (Lynch, 2005).

Si el análisis de la evolución en el tiempo permite subrayar las repercusiones del modelo de crecimiento sobre el declive posterior, aproximarse a éste desde la dimensión territorial, revela la simultaneidad de los procesos de crecimiento y declive a escala regional. La fuerte interdependencia de ambos procesos permite a su vez comprender el fracaso de toda una serie de proyectos, programas y políticas que nunca vincularon dos fenómenos interdependientes.

Finalmente, esta investigación apunta las claves para comprender las circunstancias actuales de Detroit como consecuencia de la interacción de unas dinámicas externas que determinaron su declive y unas formas de gobierno que apoyaron el modelo. Es, en este sentido, la crónica de un declive anunciado. Queda tan sólo esperar que las diversas iniciativas de la comunidad local puestas en marcha en los últimos años encuentren el apoyo institucional necesario para transformar unos modos de gobierno fuertemente arraigados en la historia de la ciudad.

\section{BIBLIOGRAFÍA}

BEAUREGARD, R.A. (1993) Voices of Decline. The postwar fate of US Cities. US: Blackwell

BEAUREGARD, R. A. (2001) "Federal Policy and Postwar Urban Decline: A Case of Government Complicity? Housing Policy Debate, vol.12, nº 1 , p.129 - 151

BEAUREGARD, R.A. (2006) When America became suburban. Minneapolis: University of Minnessota Press

CONOT, R. (1974) American Odyssey. Nueva York: William Morrow \& Co

DARDEN, J.T, HILL, R.C., THOMAS, J.M, THOMAS, R. (1987) Detroit: Race and Uneven Development. Philadelphia: Temple University Press 
DAVIS, D.F. (1988) Conspicuous production: automobiles and elites in Detroit, 1899-1933. Philapdelphia: Temple University Press

DETROIT CITY PLAN COMMISSION (1919) A Building Zone Plan for Detroit. Detroit: Detroit City Plan Commission

DETROIT CITY PLAN COMMISSION (1944a). The economic base. Detroit: Detroit City Plan Commission

DETROIT CITY PLAN COMMISSION (1944b). Toward a Greater Detroit. Looking ahead with the City Plan Commission. Detroit: Detroit City Plan Commission

DETROIT CITY PLAN COMMISSION (1946a). The People of Detroit. Master Plan Reports. Detroit: Detroit City Plan Commission,

DETROIT CITY PLAN COMMISSION (1946b). Proposed System of Trafficways, Detroit: Detroit City Plan Commission,

DETROIT CITY PLAN COMMISSION (1954). Redevelopment Study. Selection of Areas and Assignment of Priorities. Detroit: Detroit City Plan Commission

DETROIT CITY PLAN COMMISSION (1956). Industrial Study. A Survey of Existing Conditions and Attitudes of Detroit's Industry. Detroit: Detroit City Plan Commission

DETROIT CITY PLAN COMMISSION (1962). Renewal and Revenue: an evaluation of the urban renewal program in Detroit. Detroit: Detroit City Plan Commission.

DIGAETANO, A. y LAWLESS, P. (1999) "Urban Governance and Industrial Decline: Governing Structures and Policy Agendas in Birmingham and Sheffield, England, and Detroit, Michigan, 1980-1997” Urban Affairs Review vol.34, n4, p.546-577

EWEN, L.A. (1978) Corporate Power and Urban Crisis in Detroit. Princeton, New jersey: Princeton University Press

FARLEY, R., DANZINGER, S.H., HOLZER, H.J. (2000) Detroit divided. New York: Russell Sage Foundation

FARMER, S. (1884) The history of Detroit and Michigan or the Metropolis Illustrated. A chronological cyclopaedia of the past and present. Detroit: Silas Farmer \& Co,

FERNÁNDEZ ÁGUEDA, B. (2012) "Planificación urbana y declive industrial: el papel del planeamiento en la evolución de la estructura productiva de Detroit tras la segunda guerra mundial” Sociología del Trabajo, n74, p. 93-120

FERNÁNDEZ ÁGUEDA, B (2013) Futuros urbanos: la reversibilidad del proceso de deterioro. Tesis doctoral. Escuela Técnica Superior de Arquitectura de la Universidad Politécnica de Madrid,

FRIEDRICHS, J. (1993) “A Theory of Urban Decline: Economy, Demography and Political Elites”. Urban Studies, vol. 30, n6, p. 907 - 917

GALLAGHER, J. (2010) Reimagining Detroit. Opportunities for Redefining an American City. Detroit: Wayne State University Press

HAYS, R.A. (1985) The federal government \& Urban Housing. Ideology and Change in Public Policy. New York: State University of New York, 
HILL, R.C. (1983) "Crisis in the Motor City: The Politics of Economic Development in Detroit” en FAINSTEIN, S.S. et Al. Restructuring the City. The Political Economy of Urban Redevelopment. New York: Longman

KLEPPER, S. (2001) "The Evolution of the U.S. Automobile Industry and Detroit as its Capital". Conferencia en The Druid Academy, http://www.druid.dk/conferences/winter2002/gallery/klepper.pdf (acceso 4-1-2015)

KORNHAUSER, A. (1952) Detroit as the People See It. A survey of attitudes in an industrial city. Detroit: Wayne University Press

LEONARD, J.W (1887). The Industries of Detroit. Detroit: J.M.Elster \& Co Publishers, 1887

LYNCH, K (2005) Echar a perder. Un análisis del deterioro. Barcelona: GG

MANCUSO, F. (1980). Las experiencias del zoning. Barcelona: Ediciones GG

MANDELL, L. (1975) Industrial Location Decisions. Detroit Compared with Atlanta and Chicago. New York: Praeger

MEYER, D.R. (1983) "Emergence of the American manufacturing belt, an interpretation” Journal of Historical Geography, vol.9, n'2, p. 145-174

MUELLER, E., WILKEN, A. y WOOD, M. (1961) Location Decisions and Industrial Mobility in Michigan 1961. A Sample Survey of Michigan and Ohio Manufacturers. Michigan: Survey Research Center. Institute for Social Research. University of Michigan,

ORR, M.E. y STOKER, G. (1994) "Urban Regimes and Leadership in Detroit" Urban Affairs Review vol.30, n ${ }^{\circ}$, p.48-73

PARK, R.E, BURGESS, E.W y MCKENZIE, R.D. (1925) The city. Chicago, The University of Chicago, (reimpresión, 1984)

POËTE, M. (1931). Une vie de cité. Paris de sa naissance à nos jours. Paris : A. Picard

RAE, J.B. (1984) The American Automobile Industry. Boston, Massachusetts: Twayne Publishers

RUIZ SANCHEZ, J. (2002) Complejidad urbana y determinación. Estructuras comunicativas y planeamiento urbano en el desarrollo del Área Metropolitana de Madrid. Madrid: Universidad Carlos III-BOEe,

RUIZ SANCHEZ, J. (2012) “Ciudad, complejidad y energía” Ciudad y Territorio. Estudios territoriales, $\mathrm{n}^{\circ} 171, \mathrm{p} .73-86$

SABEL, CH. y ZEITLIN, J. (1985) "Historical Alternatives to Mass Production: Politics, Markets and Technology in Nineteenth- Century Industrialization” Past \& Present, $\mathrm{N}^{\circ} .108$, p. 133-176

SUGRUE, Th (1996). The origins of the urban crisis. Race and Inequality in Postwar Detroit. Princeton: Princeton University Press

SUTCLIFFE, A. (1981) Towards the planned city. Germany, Britain, the United States and France, 1780-1914. Oxford, Basil Blackwell

THOMAS, J.M. (1988) "Racial Crisis and the Fall of the Detroit City Plan Commission”, Journal of the American Planning Association, 54.2, p. 150-161 
THOMAS, J.M. (1990) “Attacking Economic Blight in Postwar Detroit”. The Society for American City and Regional Planning History, The Working Paper Series. Denver: University of Colorado at Denver,

THOMAS, J.M. (1997) Redevelopment and Race. Planning a Finer City in Postwar Detroit. Baltimore: The Johns Hopkins University Press

ZUNZ, O. (1977) "The organization of the American City in the late Nineteenth Century: Ethnic Structure and Spatial Arrangement in Detroit” Journal of Urban History, 3.4, p.443-466

ZUNZ, O. (1982) The Changing Face of Inequality: Urbanization, Industrial Development, and Immigrants in Detroit, 1880-1920. Chicago: University of Chicago Press http://www2.lib.virginia.edu/ccdb

www.census.gov (Censos históricos de 1880 a 2010) 